\title{
MATERIALES CERÁMICOS DE LOS HORIZONTES PÚNICOS DEL CASTILLO DE IBIZA, EXCAVACIONES DE 1988-1989
}

\section{CERAMIC MATERIALS FROM THE PUNIC HORIZONS OF THE CASTLE OF IBIZA, EXCAVATIONS OF 1988-1989}

\section{Joan RAMON TORRES}

\begin{abstract}
Departamento de Patrimonio Histórico, Consejo de Ibiza, Avenida España 49, 07800, Ibiza Correo electrónico: joanramontorres@gmail.com
\end{abstract}

\begin{abstract}
Resumen: Se estudian en el presente artículo los materiales cerámicos procedentes de una excavación preventiva realizada en el castillo de Ibiza entre los años 1988 y 1989. Se trata de elementos, principalmente vasculares, fechados sobre todo entre los últimos decenios del siglo $\mathrm{V}$ y mediados del II a.C., dejando aparte otros de época fenicia, fechados en este caso en los dos primeros tercios del siglo VI a.C. El estudio y publicación de estos complejos, algunos de ellos estratificados, tiene el interés añadido de ser el primero que se lleva a cabo en el área de la acrópolis púnica de Ibiza y este hecho permite toda una serie de precisiones cronológicas, así como observaciones de otro género resultantes de su comparación con otros yacimientos púnicos de la isla contemporáneos al Castillo de Ibiza.
\end{abstract}

Palabras Clave: Ibiza, castillo, época púnica, cerámica vascular, secuencia cronológica.

Abstract: In this article, the ceramic materials from a preventive excavation carried out in the castle of Ibiza between the years 1988 and 1989 are studied. These are elements, vascular the majority, dated mainly between the last decades of the 5 th century and the middle of the 2 nd century BC., leaving aside others from the Phoenician period, in this case dated to the first two thirds of the 6th century BC. The study and publication of these complexes, some of them stratified, has the added interest of being the first to be carried out in the area of the Punic acropolis of Ibiza, and this fact allows a whole series of chronological details, as well as observations of another genre resulting from its comparison with other Punic sites on the island contemporary to the Castle of Ibiza.

Keywords: Ibiza, castle, Punic period, vascular pottery, chronological sequence.

Sumario: En homenaje. 1. Presentación. 2. Los contextos estratigráficos. 3. Estudio de los materiales. 3.1. Ánforas. 3.2. Contenedores medianos y pequeños. 3.3. Vajilla. 3.4. Cerámica de cocción/calentamiento. 3.5. Cerámica de iluminación. 3.6. Varia vascular. 3.7. Cerámica no vascular. 4. Valoración. 5. Bibliografía. 6. Apéndice.

\section{En homenaje}

Tuve el placer de conocer a Antonio Sáez Espligares a finales de 1998, a raíz de una visita al Museo de San Fernando. Su carácter afable y su dedicación a dicho museo, del cual era entonces subdirector, me impulsaron a promover el estudio de un importante conjunto de materiales que él restauró y custodiaba con sumo cariño y que procedían de una intervención preventiva en el sector III de Camposoto. Ello dio paso a una fructífera colaboración y amistad que culminó en la publicación científica de dichos materiales. Al recibir, hace algunos meses, la invitación de participar en este muy merecido homenaje, no pude menos que recordar también el esfuerzo de Antonio en la recuperación del castillo de San Romualdo. Entonces, tuvimos ocasión de comparar e intercambiar opiniones entre el castillo de San Fernando y el de Ibiza y esta es la razón del presente artículo, que le dedico con afecto y admiración.

\section{Presentación}

Han pasado treinta y dos años desde que se realizara la excavación cuyos materiales cerámicos de época púnica son objeto del presente trabajo y, sin 
embargo, su interés no ha perdido vigencia. Ello se explica por el simple hecho que de toda la parte urbana de la antigua ciudad de Ibiza no se han dado a conocer hasta la fecha otros conjuntos similares, siendo en realidad escasos los hallazgos homogéneos de este tipo.

En la propia Ibiza, y a un nivel más general, tampoco es mucho lo dado a conocer acerca de grupos de cultura material, especialmente de carácter vascular, de los siglos III y II a.C. En este sentido, cabe recordar que fuera de los muy específicos y selectivos ámbitos funerario y alfarero, sólo se dispone del conjunto hallado en un pozo en las cercanías de la ciudad antigua, denominado HX-1 (tercer cuarto del siglo III a.C.) (Ramon, 1994a) y de los conjuntos de s'Olivar des Mallorquí (finales del siglo III a.C.) (Gómez, 1995) y can Vicent d'en Jaume (tercer cuarto del siglo II a.C.) (Pérez y Gómez, 2009).

Una pregunta que, de entrada, viene al caso, es si la componenda material en un lugar tan emblemático, como la cúspide de la acrópolis de la Ibiza púnica (Figura 1A), es -y entonces hasta qué punto- comparable a la de los mencionados sitios de carácter rural, que en el caso de Olivar des Mallorquí y de can Jaume se hallan además muy alejados de la ciudad.

Otra cuestión interesante, y que se abordará aquí, es la presencia y balance relativo de elementos de importación. Como es sabido, tanto los conjuntos alfareros antes aludidos (Ramon, 19901991, 1997, 2011), como los mobiliarios funerarios ibicencos de esta época, aunque en cantidades pequeñas, contienen elementos foráneos, pero entonces la pregunta es sí las proporciones y su naturaleza son las mismas.

Cabe recordar la situación del castillo, en el óvalo culminante de la acrópolis fenicio-púnica, después romana que, en ocasiones, se ha sugerido sede de construcciones singulares, como fortificaciones, santuarios o edificios públicos (Ramon, 2000: 138-139). Veremos también si las características de los materiales muebles analizados tienen algo que decir al respecto.

Cabe aún señalar, antes de entrar en materia, que una parte considerable de los tipos vasculares documentados en las excavaciones del castillo de Ibiza es de antemano conocida, aunque con mayor o menor amplitud según cada caso concreto y, por ello, la profundidad del discurso irá en función de cada circunstancia, resaltando, cuando proceda, las eventuales precisiones que el castillo de Ibiza pueda aportar; de hecho, no se pretende ahora un estudio en profundidad de todos los elementos de esta clase, que en detalle son muy variados y extensos, así como tampoco un análisis geográficamente amplio de los objetos de importación. Lo principal en este momento es su encuadre técnico, utilizando sólo bibliografía de generación reciente o última y, sobre todo, su presentación.

A nivel de contextualización histórica, los materiales que se estudian a continuación, dejando de lado unos pocos fragmentos de época fenicia, se enmarcan cronológicamente hablando entre los últimos decenios del siglo $\mathrm{V}$ y c. 150 a.C. Abstracción hecha de que los fragmentos fechables en el siglo V y IV a.C. se hallan generalmente en posición residual, pero que demuestran la ocupación del castillo de Ibiza en este momento, el grueso de materiales, en realidad, corresponde a una fase que abarca prácticamente las tres Guerras Púnicas.

En este sentido, cabe recordar los pocos textos sobre la isla recogidos en las fuentes clásicas, donde tiene una especial relevancia la descripción que Diodoro de Sicilia (Biblio. Hist., V, 16-18) tomaría prestada de Timeo de Taormina, este último a caballo de los siglos IV y III a.C. En dicho parágrafo se habla de una ciudad colonia de Cartagineses, con casas bien construidas en número abundante, grandes murallas y puertos dignos de mención. En efecto, esta realidad, bien constatada antaño a partir de la necrópolis urbana del Puig des Molins, ha sido confirmada por la arqueología en fechas más recientes, que además ha podido definir una muy extensa área urbana de época púnica (Figura 1A). Por otro lado, se ha podido comprobar una sistemática colonización agrícola de toda la isla, ya a partir de la segunda mitad del siglo $\mathrm{V}$ a.C., con una especialización en monocultivos para, de modo particular, la elaboración de vino, hecho que no ha venido sino a corroborar algo que desde antes se vislumbraba de forma clara a través de su amplia exportación anfórica.

Mientras que es difícil discernir hasta que punto las vicisitudes de Cartago pudieron afectar Ibiza en la época de la Primera Guerra Púnica y la subsecuente Guerra de los Mercenarios, que cubrieron una parte significativa de los cuartos centrales del siglo III a.C., para la segunda contienda existen datos más directos. Aquí cabe recordar de modo muy especial dos parágrafos de Tito Livio, el primero narrando la inutilidad de un asedio a la capital ibicenca comandado por Cneo Cornelio Escipión (217 a.C.) (Ab urbe ... XXII, 20, 7) y, en contrapar- 

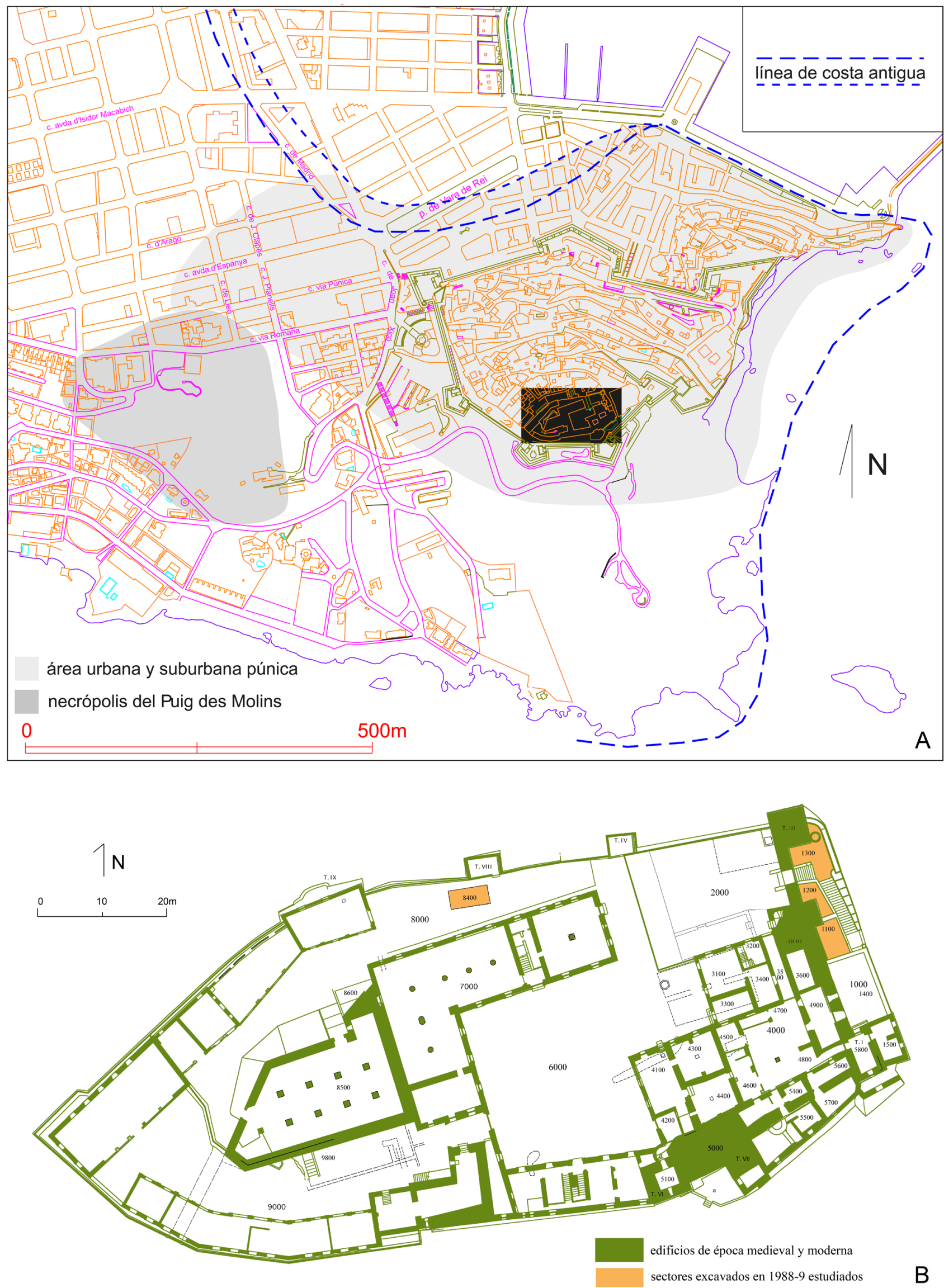

B

Figura 1. A. plano general de la ciudad de Ibiza (el recuadro negro corresponde con B). B. plano del castillo con indicación de los sectores 1998-9 estudiados.

Revista Atlántica-Mediterránea de Prehistoria y Arqueología Social 22, pp. 79-107 Universidad de Cádiz 
tida, el cuantioso botín obtenido por los romanos en el saqueo del campo ebusitano y, el segundo, dando cuenta de la buena acogida que tuvo la flota de Magón, tras retirarse de Gadir en el año 206 a.C., junto con su aprovisionamiento en hombres, armas y víveres (Ab urbe ... XXVIII, 37, 3).

Cabe remarcar que Livio, cuando a raíz de la presencia de la flota de Magón cita Ibiza, remarca Poeni tum eam incolebant, hecho que no hace sino incidir en el carácter cartaginés de la isla, atendiendo las nomenclaturas del escritor republicano. En cualquiera de los casos, lo ocurrido entre el final de la Segunda Guerra Púnica (201 a.C.) y el momento en el cual Ebusus firmó con Roma un tratado de federación, sigue siendo un misterio. Dicho tratado, que no aparece citado más que en Plinio el Viejo (Nat. Hist., 76-77), se quiso hacer coincidir en tiempo y forma con el de Gadir, presuponiendo rendición previa de la isla. Hoy se tiende a considerarlo, o bien en el contexto de las Guerras Sertorianas, o bien, en época de Julio César, en algunos de cuyos acontecimientos y en diferente media, Ibiza se vio involucrada.

Pero dejando de lado estos momentos tan tardíos de la República Romana, lo que interesa remarcar (y aquí los materiales que se van a estudiar, también contribuyen a ello) es que hasta su destrucción final en el 146, Cartago e Ibiza fueron muy de la mano en cuanto a actividades comerciales y, tal vez, incluso políticas. Sólo ello, y no la conquista de las vecinas Mallorca y Menorca por parte de Metelo en el 121 a.C., podría explicar muchas cuestiones que arqueológicamente hablando se plantean en Ibiza, como por ejemplo la formación de muchos depósitos hacia el 150 a.C. o primeros años del tercer cuarto del siglo II a.C. (mayoritariamente inéditos), seguida de una apreciable oscuridad en el registro. El castillo de Ibiza podría ser uno más de tales ejemplos.

\section{Los contextos estratigráficos}

Sobre el castillo de Ibiza fue publicada una monografía de carácter general (Ramon, 2000) que, entre otras muchas cuestiones, incorporó los principales resultados de la excavación preventiva de 1988-1989. En esta circunstancia se dieron a conocer todas las planimetrías, incluidas secciones estratigráficas, junto con los comentarios de orden secuencial y cronológico, que se consideraron oportunos. Sin embargo, los materiales únicamente fueron inventariados e inspeccionados de modo preliminar, sin llegar a estudiarlos en profundidad ni a publicarlos.

Los que interesan ahora proceden de dos de las zonas en las cuales convencionalmente fue subdividido el amplio recinto del castillo-almudaina, la zona 1000 y la zona 8000 (Figura 1B), no habiendo el resto proporcionado materiales de época púnica debido, en unos casos, a intervenciones en obra demasiado superficiales para ello y al simple arrasamiento de los niveles antiguos en el largo transcurso de su historia posterior, en otros.

La zona 1000 se sitúa en el costado externo del paramento E de la fortificación del castillo enmarcado por las torres I-III, y, más exactamente frente a las torres II y III que, dicho sea de paso, cortan toda la estratigrafía hasta asentarse en el substrato rocoso.

En el sector 1100 (Ramon, 2000: 24-17, fig. 6-10), aunque se localizó un fondo de casa y una cisterna púnica, la estratificación correspondiente apareció literalmente barrida por reformas y reutilizaciones de época medieval y moderna, no proporcionando elementos como los que interesan ahora.

Por su parte, el sector 1200 (Ramon, 2000: 17-19, fig. 11-14) fue el que ofreció una mejor secuencia y una mayor homogeneidad. En este contexto destacan las UEs $1211 \mathrm{y}$, por debajo de ella, la 1212, cubriendo el corte rocoso en horizontal, atribuido a un fondo de estancia púnica y enmarcado, por el $\mathrm{N}$, por un muro púnico de sillares de arenisca (UE1214). Le UE1211 apareció cortada, también en horizontal, en su parte superior por una fosa con una amplia estratificación de época vándala, que fue estudiada y publicada hace años (Ramon y Cau, 1997).

El estrato inferior, UE1212, con una potencia de no más de $8 \mathrm{~cm}$, aportó un corto, pero muy interesante, conjunto de materiales de época púnica (Figura 2), incluso algo más íntegros que los que después se verán en otras unidades, junto con un clavo de hierro, algunos fragmentos de revestimientos de edificios y restos óseos de fauna doméstica.

Aparte de algunos fragmentos de cuerpos acanalados, los envases industriales se redujeron a un borde de ánfora PE-22 (1212/1). Algo más rico era el elenco de contenedores medianos y pequeños, que se sintetiza en la presencia de al menos dos jarras ebusitanas tipo $\mathrm{C} 2 / 15$, una de ellas conservando todo el tercio superior $(1212 / 2,1212 / 17)$, otras dos, atribuibles al tipo RA-91/69, con líneas 
horizontales rojas $(1212 / 4,1212 / 8)$, el borde y parte superior del cuello de una jarra Eb77, no decorada (1212/5). Cabe añadir un fragmento de cuerpo Askos ebusitano, conservando tres líneas horizontales de pintura roja (1212/9), así como diversos fragmentos de jarros/as eb. no clasificables debido a su fragmentación, decorados con líneas y/o trazos horizontales de pintura roja en la cara externa $(1212 / 3,1212 / 10,1212 / 11)$ o sin ella, al menos en los fragmentos conservados $(1212 / 6,1212 / 38)$. Existe también un asa geminada de jarro/a eb. no clasificable (1212/41), por un problema de excesiva fragmentación, que afecta otras piezas (1212/12, 1212/13 1212/14). Mención aparte, por su interés y porqué genera problemas de orden cronológico, merece un fragmento de cuello y espalda de jarra eb. no clasificada, con grafito post coctionem, conservando tres letras en lengua púnica tardía (1212/7) (cf. José A. Zamora en apéndice). No puede descartarse un error en la atribución de esta pieza a la UE1212 y a la superpuesta 1211, aunque en cualquiera de los casos el fragmento no puede ser posterior a mediados del siglo II a.C.

Se registra, además, un fondo rehundido de jarro africano tampoco clasificable (1212/15) y un fragmento de cuerpo de gran jarra o ánfora también africana y el tercio superior de un jarrito bicónico ibérico gris $(1212 / 16)$ con nervios horizontales. Destaca, además, el borde, cuello y espalda de ungüentario globular de importación, decorado con múltiples líneas rojas horizontales finas $(1212 / 18)$.

En cuanto a vajilla de mesa, atribuidos a versiones ebusitanas derivadas de los outturned rim bowl de barniz negro áticos (Fernández y Granados, 1980 tipo 2.4 / 2.5 = Guerrero 1999, fig. 6 tipo A.1.I.4.a), tres ejemplares presentan roseta estampillada en el centro de su fondo interno (1212/19, $1212 / 20$ y $1212 / 21$ ) (Figuras 2 y 10), mientras que en otras dos piezas de este tipo este elemento decorativo falta, al faltar la parte donde se imprime (1212/22 y 1212/23).

Siguiendo con la vajilla ibicenca, pero en este caso de pasta oxidante, tratada con baño de pintura roja/negra, se registra un cuenco L26/27 $(1212 / 24)$, uno L25 $(1212 / 25)$, un plato L23 $(1212 / 26)$, un cuenco tipo HX-1/53 (1212/27), otro cuenco probablemente L27 (1212/35), además de un cuenco gris, con pintura gris oscuro $(1212 / 39)$. Tres elementos sin decoración cierran el repertorio de vajilla, se trata de un cuenco con- vexo, de formato grande, tipo AE-20/I-136 (Ramon, 1990-1991, fig. 6) $(1212 / 28)$, otro tipo AE20/I-139 (Ramon, 1990-1991, fig. 6) (1212/30) y, finalmente, un plato que conserva el perfil completo tipo C.212/32 (1212/32-33).

En cuanto a cerámica de procesamiento eb., un cuenco pertenece al tipo AE-20/I-143 (Ramon, 1990-1991, fig. 6) (1212/29) y un mortero al tipo AE-20/I-167 (1212/31), existe además una base anular de cuenco grande, sin decoración, de tipo no precisable $(1212 / 34)$. Una olla convexa tipo AE-34/II-203 (1212/36) cierra este repertorio.

Otros elementos en este estrato son un discoide en cuerpo de ánfora T-8121 prob (1212/37), un clavo de hierro de sección circular fragmentario $(1212 / 40)$ y diversas muestras de fauna doméstica $(1212 / 42)$.

La UE1211, de mayor potencia (hasta $28 \mathrm{~cm}$ ), y por encima de la anterior, aportó un número de fragmentos cerámicos clasificables superior a 150 unidades y, además, fauna doméstica, restos de carbones, monedas de la ceca de Ibiza y otros elementos metálicos, así como fragmentos de pavimentos y revoques. Como sucede en general, los fragmentos cerámicos se hallan muy fragmentados y muchos de ellos reflejan impactos que, con claridad, indican una reducción intencionada, con la finalidad de ahorrar volumen, una vez rotos o amortizados, práctica generalizada, al menos en Ibiza, en la Antigüedad. El repertorio cerámico de la UE1211 es el siguiente:

Bordes de ánforas (Figura 3): uno atribuido al T-8121 (1211/1), cuatro al T-8132 (1211/2-5), fragmentos de asas y puntas $(1211 / 6-10,16)$ de cualquiera de los dos tipos. Greco-itálicas de aspecto tardío y pasta férrica $(1211 / 11,1211 / 13$ 14), además de otra de tipo antiguo y pasta volcánica $(1211 / 15)$. Pivote de ánfora púnica africana del G-7400 (1211/89), cuerpo inclasificable de la misma procedencia (1211/12) y fragmento de ánfora ibérica (1211/92).

Contenedores eb. medianos y reducidos con forma asignable (Figura 3): Eb69 (1211/17, $1211 / 22,1211 / 23-25,1211 / 33,1211 / 36$, $1211 / 40,1211 / 41,1211 / 44,1211 / 60)$, Eb76 (1211/61), Eb77 (1211/17, 1211/21, 1211/30, $1211 / 45,1211 / 46,1211 / 47,1211 / 48)$, C2/15 (1211/19), Eb73a (1211/26), hydria (1211/37), bordes no clasificados $(1211 / 20,28)$, askoi (1211/32, 1211/43, 1211/50, 1211/51, 1211/58, $1211 / 59,1211 / 68,1211 / 69,1211 / 72,1211 / 85$, $1211 / 118)$, Eb13c (1211/42, 1211/49). No clasi- 


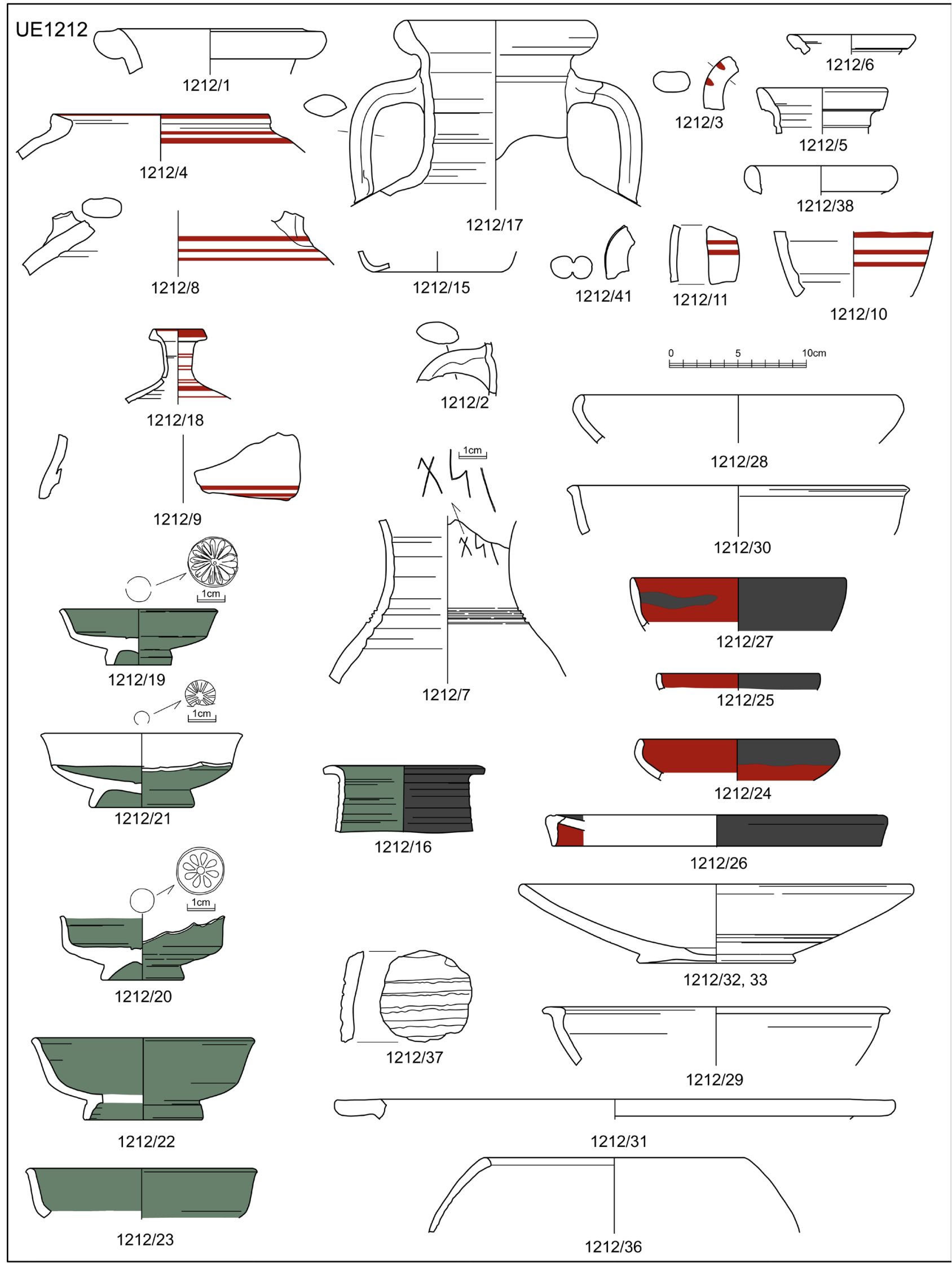

Figura 2. Materiales de la UE1212.

Revista Atlántica-Mediterránea de Prehistoria y Arqueología Social 2, pp. 79-107 Universidad de Cádiz 


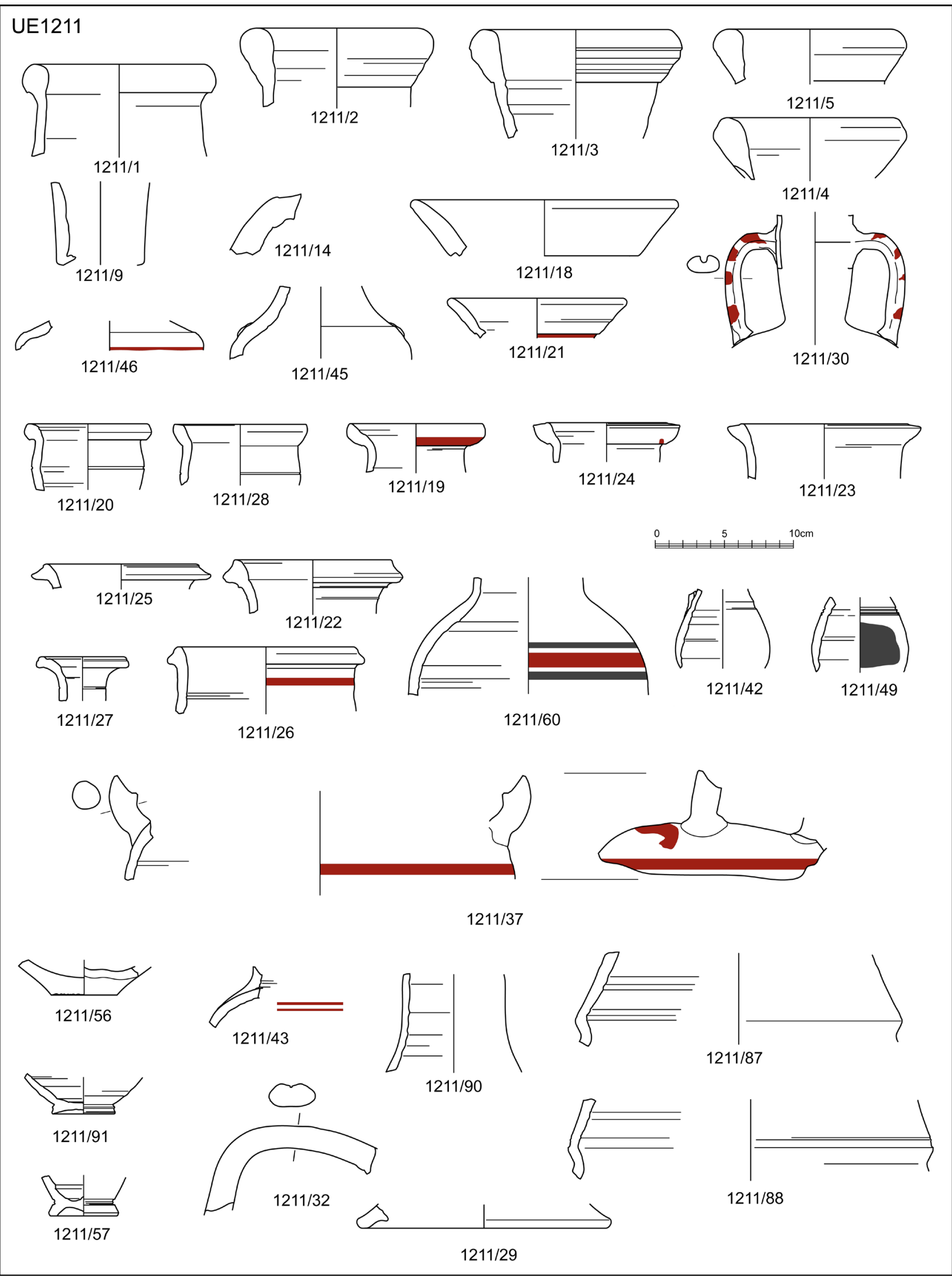

Figura 3. Materiales de la UE1211.

Revista Atlántica-Mediterránea de Prehistoria y Arqueología Social 22, pp. 79-107 
ficables (por ser fragmentos demasiado polivalentes) conservando decoración, generalmente de líneas horizontales pintadas y, más raramente otros motivos complementarios $(1211 / 31,1211 / 62-67$, $1211 / 70,1211 / 71,1211 / 73-83,1211 / 93)$. Como los anteriores, pero sin decoración, al menos en la parte del fragmento conservada (1211/34, 1211/35, 1211/52-54, 1211/56, 1211/86-88). En cuanto a contenedores mediano-pequeños de importación (Figura 2), se registra una base completa de pequeño jarrito (1211/57 de producción africana, 1211/91 de producción indeterminada) y el cuello de un jarro mediano africano (1211/90).

Vajilla ebusitana con baño de pintura roja y/o negra (Figura 4): cuencos carenados (Guerrero, 1999, fig. 8-8a tipo A.1.I.5.a) (1211/97, 1211/99, 1211/99bis), copa L27 (1211/103, 103), plato L23 (1211/104, 105), pátera L55 (Guerrero, 1999, fig. 15 tipo A.1.II.5.b) (1211/106), paterita pequeña (Guerrero, 1999, fig. 14 tipo A.1.II.5.a) (1211/107), copa muy convexa pequeña $(1211 / 108)$, cuenco o copa con borde triangular exvasado, no clasificada (1211/109).

Vajilla ebusitana en cerámica gris: copa outturned rim bowl (Guerrero, 1999, fig. 6 tipo A.1.I.4.a) (1211/98), copa L28 (1211/100 gris), copa L27 (Guerrero, 1999, fig. 4 tipo A.1.I.2.b.) (1211/101).

Vajilla ebusitana sin decoración (Figura 4): cuenco convexo (1211/115), plato de borde moldurado tipo FE-13/91 (= Guerrero 1999, fig. 16, 1-2 tipo A.1.II.6) (1211/116).

Vajilla importada. Campaniense A (Figura 4): L23 (Morel 1981 F1120) (1211/149), L27a-b (Morel 1981 F2784, 2788) (1211/140-142), L28a-b (Morel 1981 F2612-2614, 2641-2648, 2654) (1211/143,5, 1211/144, 1211/146), L36 (Morel 1981 F1312-1314) (1211/148), L48A (Morel 1981 F3155) (1211/153), L33b (Morel 1981 F2973-2974, 2985) (1211/147). Calena Antigua (Figura 4): píxide Morel 1981 F7510 (1211/150,1), L36 (1211/152). Además, se registraron cuatro fragmentos no clasificables de campaniense A y dos de Calena Antigua, aunque uno de ellos tal vez pertenezca a la B etrusca.

Cerámica de procesamiento ebusitana (Figura 4). Grandes cuencos convexos, con apliques en el borde tipo FE-13/273 (= Guerrero, 1999, fig. 83 tipo C.1.II.1.) (1211/112, 1211/113), mortero de borde horizontal con ápice redondeado (1211/110), mortero tipo C.1.I.1 (Guerrero, 1999, fig. 80, 4) (1211/114).

Cerámica de cocción y/o calentamiento ebu- sitana (Figura 5): olla o cazuela (Guerrero, 1999, fig. 94,1 tipo D.1.I.2.) $(1211 / 123,1211 / 124$, $1211 / 126,1211 / 132)$, gran olla convexa tipo AE34/II-203 (1211/125), ¿soporte? (Guerrero, 1999, fig. 94, 2, pero no clasificado) $(1211 / 127)$, tapadera de olla o cazuela (Guerrero, 1999, fig. 102 tipo D.1.VI.1). (1211/117, 1211/128, 1211/129), jarro de calentamiento (Guerrero, 1999, fig. 100, 2 tipo D.1.IV.1.) (1211/130), olla tipo FE-13/308 (1211/131), (1211/133). Cabe remarcar que en este estrato algunas bases de ollas eb., aparecieron con la cara externa completamente quemada.

Cerámica de cocción africana (Figura 5): borde de olla producción africana, pátina rojiza exterior (1211/134) (Guerrero, 1999, fig. 105, 1, tipo D.2.I.2.), cazuela africana red black top ware Vegas (1999, F.69, fig. 107 = Guerrero, 1999, fig. 112, 2-4 tipo D.2.II.2.) (1211/136), asa de olla africana red black top ware (Guerrero, 1999, fig. 105, 2 tipo D.2.I.2. = Vegas 1999, F.68.3, fig. 106,1. (1211/154).

Cerámica de cocción itálica (Figura 5): cazuela Vegas (1973) tipo $14(1211 / 135)$, base y perfil inferior de tapadera (1211/137), base de cazuela tipo imprecisable (1211/138).

Otros elementos (Figura 5): soportes de brase$\operatorname{ros}(1211 / 38,1211 / 39,1211 / 84)$, base completa anular, alta y maciza, perforada verticalmente ante coctionem de vaso eb. no clasificado (1211/121), una lucerna (1211/55) y un fragmento de terracota eb. con pie de figura humana (1211/122) (Figuras 5 y 10).

Sin dejar el sector 1200 , al lado de los estratos comentados, que fueron objeto de excavación, un sondeo de poco más de un $1 \mathrm{~m} 2$ fue practicado en el ángulo SO del sector, por decisión de la dirección facultativa de la obra, y que no pudo ser estratigráficamente controlado. A pesar de ello, su vinculación con los niveles de la parte septentrional del sector antes descritos es necesaria y, el material que, por fortuna, pudo ser recogido en su totalidad, lo refleja claramente. Este último ha sido estudiado bajo la sigla UE1218, aunque cabe advertir que agrupa diversos estratos, los materiales son claramente separables a posteriori por las características y cronología de las piezas (Figura 6). Ánforas ebusitanas: T-8121 (1218/1-3 y 1218/9). Contenedores medianos eb.: jarra RA91/69 con línea horizontal ancha de pintura negra (1218/5), jarra C2/15, con el borde pintado en rojo (1218/6), jarra Eb69 antigua (1218/7), jarrito Eb13a-b o Eb23c (1218/9), oenocoe eb. de boca 


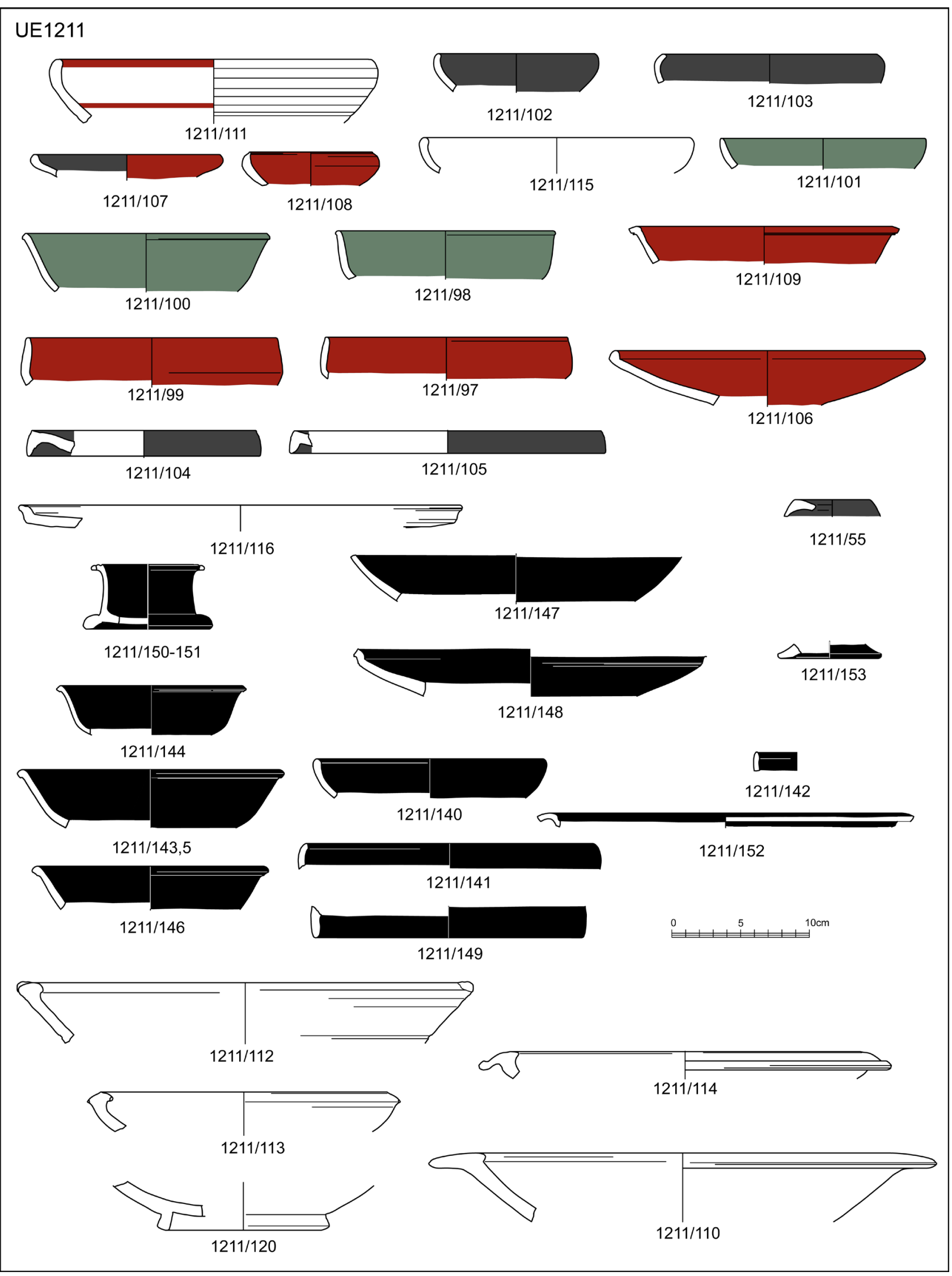

Figura 4. Materiales de la UE1211.

Revista Atlántica-Mediterránea de Prehistoria y Arqueología Social 22, pp. 79-107 Universidad de Cádiz 


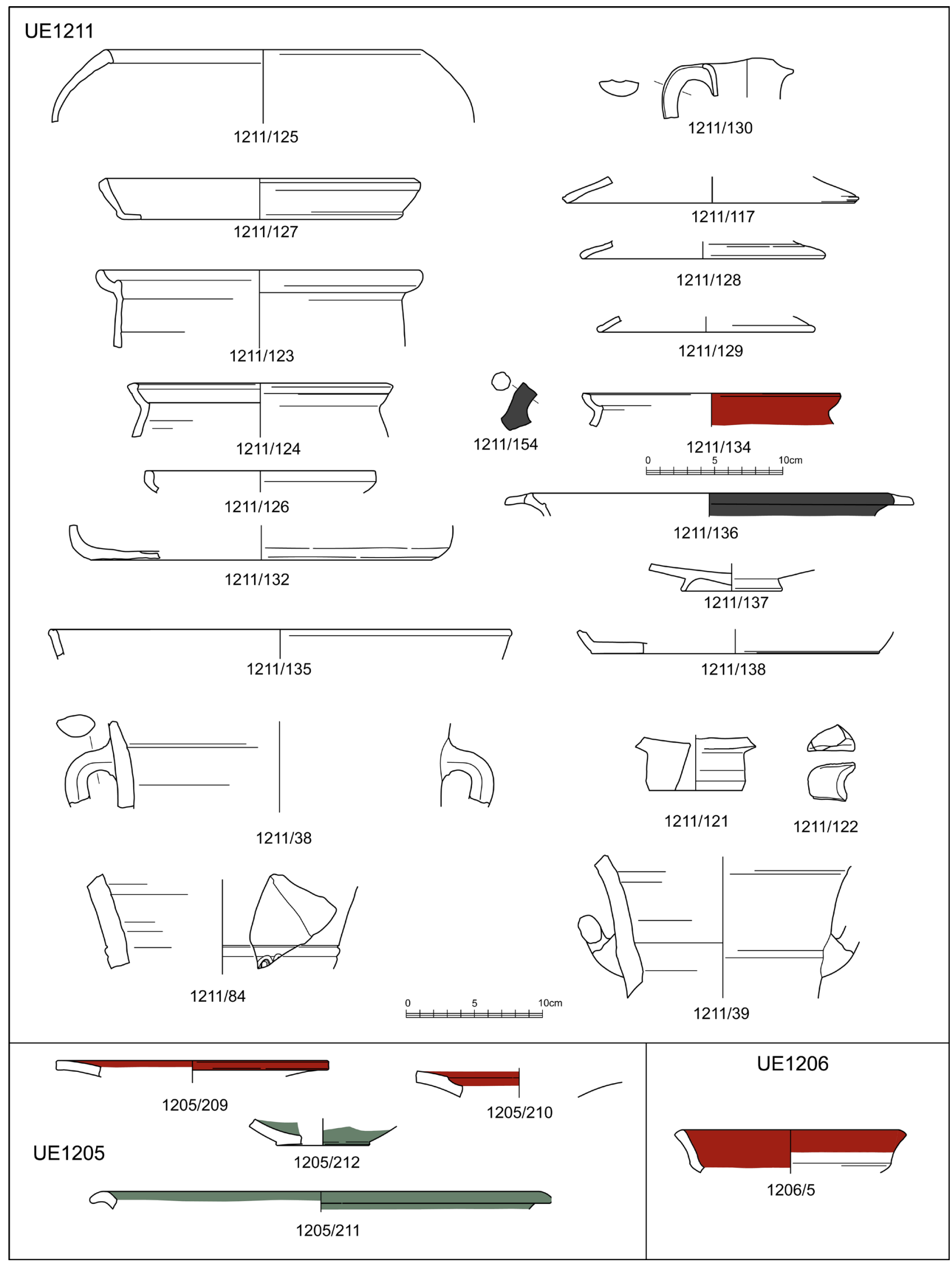

Figura 5. Materiales de la UE1211.

Revista Atlántica-Mediterránea de Prehistoria y Arqueología Social 22, pp. 79-107 Universidad de Cádiz 


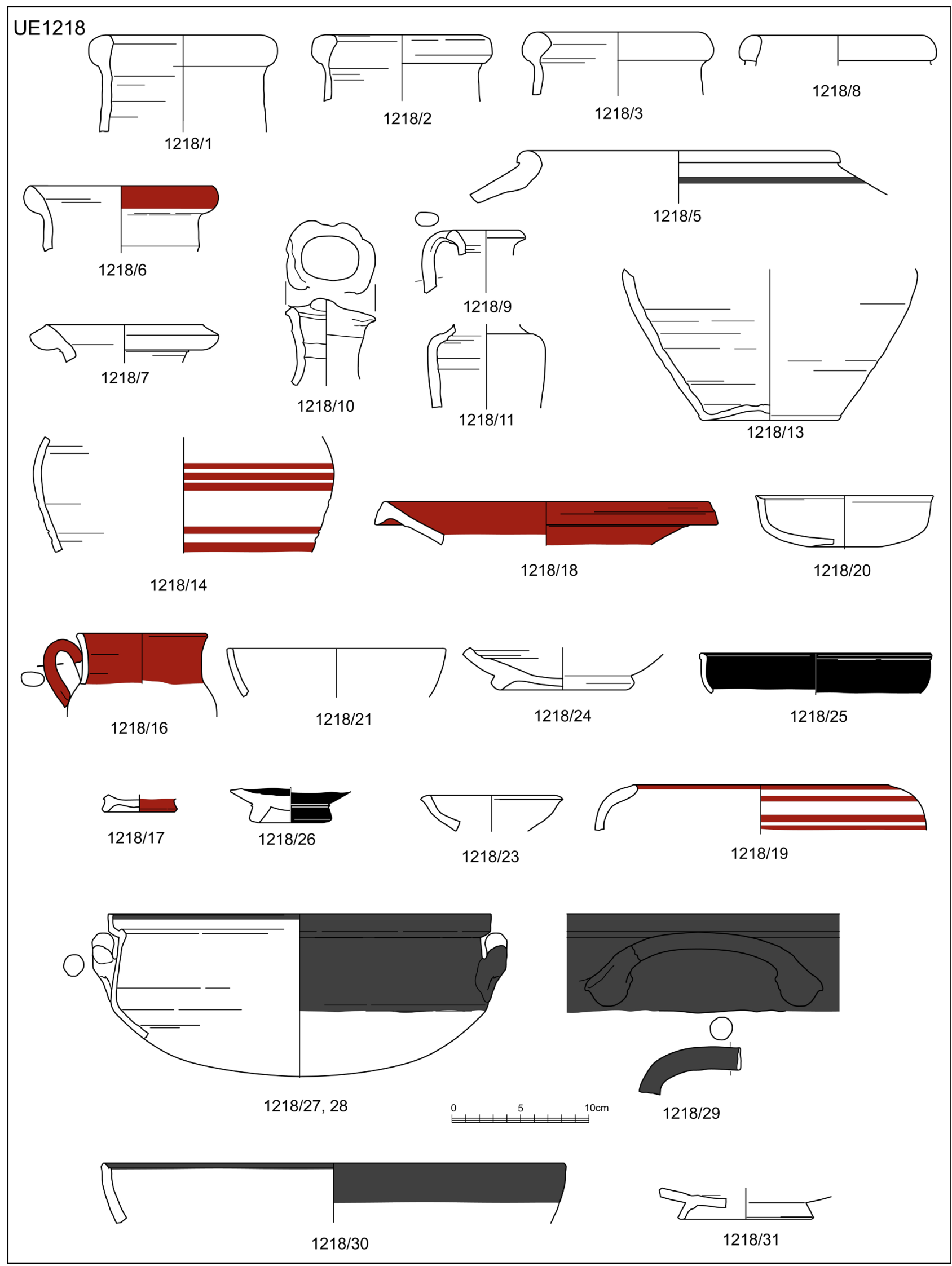

Figura 6. Materiales de la UE1218.

Revista Atlántica-Mediterránea de Prehistoria y Arqueología Social 22, pp. 79-107 Universidad de Cádiz 
trilobulada (1218/10), jarrito Eb23c (1218/11), askos (1218/12, 13), hydria B.1.VII.1. (1218/14), pequeño fragmento de jarro/a ebusitano no clasificable con línea roja horizontal (1218/15), jarritos tipo AR-33/V pintura roja en baño $(1218 / 16$, 1218/17).

Vajilla ebusitana con baño de pintura roja y/o negra: plato L23 (1218/18), cuenco muy convexo con líneas rojas horizontales en el exterior $(1218 / 19)$, cuenco de borde biselado (1218/20), cuenco no decorado y no clasificado con ocre rojo adherido (1218/24).

Vajilla de importación: cuenco outturned rim con barniz negro muy buena calidad ático o itálico $(1218 / 25)$, base y perfil inferior copa Campaniense $\mathrm{A}$, con estrías de torneado marcadas, pero no estampillada (1218/26), que en realidad es compatible con diversos de los tipos propios de esta producción, siendo imposible precisar más.

Cerámica de procesamiento ebusitana: cuenco tipo AE-20/I-125 (1218/21).

Cerámica de cocción africana: perfil completo, menos parte inferior del fondo, de cazuela red black top ware Vegas f.68.3 (1999: 197, abb. $106=$ Guerrero, 1999, fig. 109 tipo D.2.II.1.a) (1218/2728) y asa fragmentaria del mismo tipo de recipiente $(1218 / 29)$, aunque no parece de la misma pieza.

Cerámica de cocción itálica: parte superior de cazuela tipo Vegas (1973) tipo 14, con tratamiento black top $(1218 / 30)$, base y perfil inferior de tapadera de cazuela Vegas (1973) tipo 16,2 = COM-IT 7a (Bats, 1993: 361) (1218/31).

Otros: cazoleta de Thymiaterion (1218/23) y molde incompleto circular de terracota, con motivos florales y rostro femenino en el centro (1218/32). Ambas piezas son ebusitanas.

El sector 1300 (Ramon, 2000: 19-27, fig. 15-16), situado junto a las caras S y E de a torre III y en la parte septentrional de la cortina que une esta torre con la II, antes comentada, ofreció un panorama estratigráfico del todo similar al del sector 1200, hecha la salvedad, que fue afectado por remociones posteriores, sobre todo debidas al cruce de una importante canalización altoimperial y la instalación, aún posterior, de una zona de necrópolis. Pese a ello, también fue observado un fondo de estancia y la presencia superpuesta de las UEs. 1305 y 1306, cuya datación, como se verá, se sitúa a mediados del siglo II a.C. También se han seleccionado para el presente estudio materiales púnicos hallados en estratos posteriores pero que, sin duda, originalmente procedían de la mencionada alteración.
UE.1306 (Figura 7).- Bordes de ánfora T-8132 (1306/1, 1306/2), ánfora africana T-7311 (Ramon, 1995, fig. 174) (1306/3), borde escalonado de isoporte de brasero? eb. (1306/4), vaso grande con asa doble eb, no clasificado, con trazos de pintura negra (1306/5), cuello de askos eb., con un ojo en pintura roja $(1306 / 6)$, cuenco eb. tipo FE-13/273 (1306/7), base y perfil inferior de jarra Eb76 o Eb77 con franja ancha de pintura roja (1306/8), y otra del mismo tipo con línea más fina de pintura también roja (1306/9). Estrato formado alrededor de mediados del siglo II a.C.

UE.1305 (Figura 7).- Borde de ánfora T-8121 $(1305 / 1,1305 / 2)$, asa de ánfora PE $(1305 / 3)$, asa de ánfora grecoitálica antigua (1305/4), base anular y perfil inferior de cuenco o jarrito eb. no decorado (1305/5), borde y perfil superior de cuenco convexo eb. no decorado (1305/6), borde de plato eb. L23 gris (1305/7), base y perfil inferior e jarra Eb77 no decorada (1305/8), base anular y perfil inferior de cuenco eb. no decorado (1305/9), borde y perfil superior de cazuela itálica tipo COM-IT 6d (Bats, 1993: 360), con el exterior completamente quemado $(1305 / 10)$, dos cuencos de procesamiento eb. tipo FE-13/273(1305/11, 1305/12), uno de ellos conservando el típico aplique en el borde. Estrato formado alrededor de mediados del siglo II a.C.

UE.1312 (Figura 8).- (sobre fondo de la estancia) espalda de grecoitálica (1312/1).

Materiales de época púnica en estratos de cronología posterior:

UE.1301 (Figura 7).- borde de ánfora T-8132 (1301/1), asa de ánfora itálica (1301/2), borde y arranque superior del cuello de jarro Eb77 con franja de pintura roja (1301/3), asa y cuello de askos eb. con pintura roja $(1301 / 7)$, fondos rehundidos de jarras eb. Indeterminadas (1301/10, 1301/11), pie y arranques de las cazoletas de thymiaterion eb. $(1301 / 12)$, borde de cuenco carenado eb. con pintura continua negra y roja (1301/17), base cuenco eb. sin decoración $(1301 / 21)$, borde y perfil convexo de plato eb. con borde moldurado $(1301 / 26)$ tipo AR-33/V-8/9 (Ramon, 2011, fig 19).

UE.1314 (Figura 8).- borde ánfora PE-22 (1314/1), base de pátera eb. probablemente L55, con pintura roja (1314/2), cuerpo ánfora itálica de pasta férrica $(1314 / 4)$.

UE.1319 (Figura 8).- borde y tramo superior cuello de jarrita Eb77 con línea de pintura roja $(1319 / 5)$, borde de copa eb. L31 (= Guerrero, 1999, fig. 5 tipo A.1.I.3.) con pintura roja en borde 
Materiales cerámicos de los horizontes púnicos del Castillo de Ibiza, excavaciones de 1988-1989

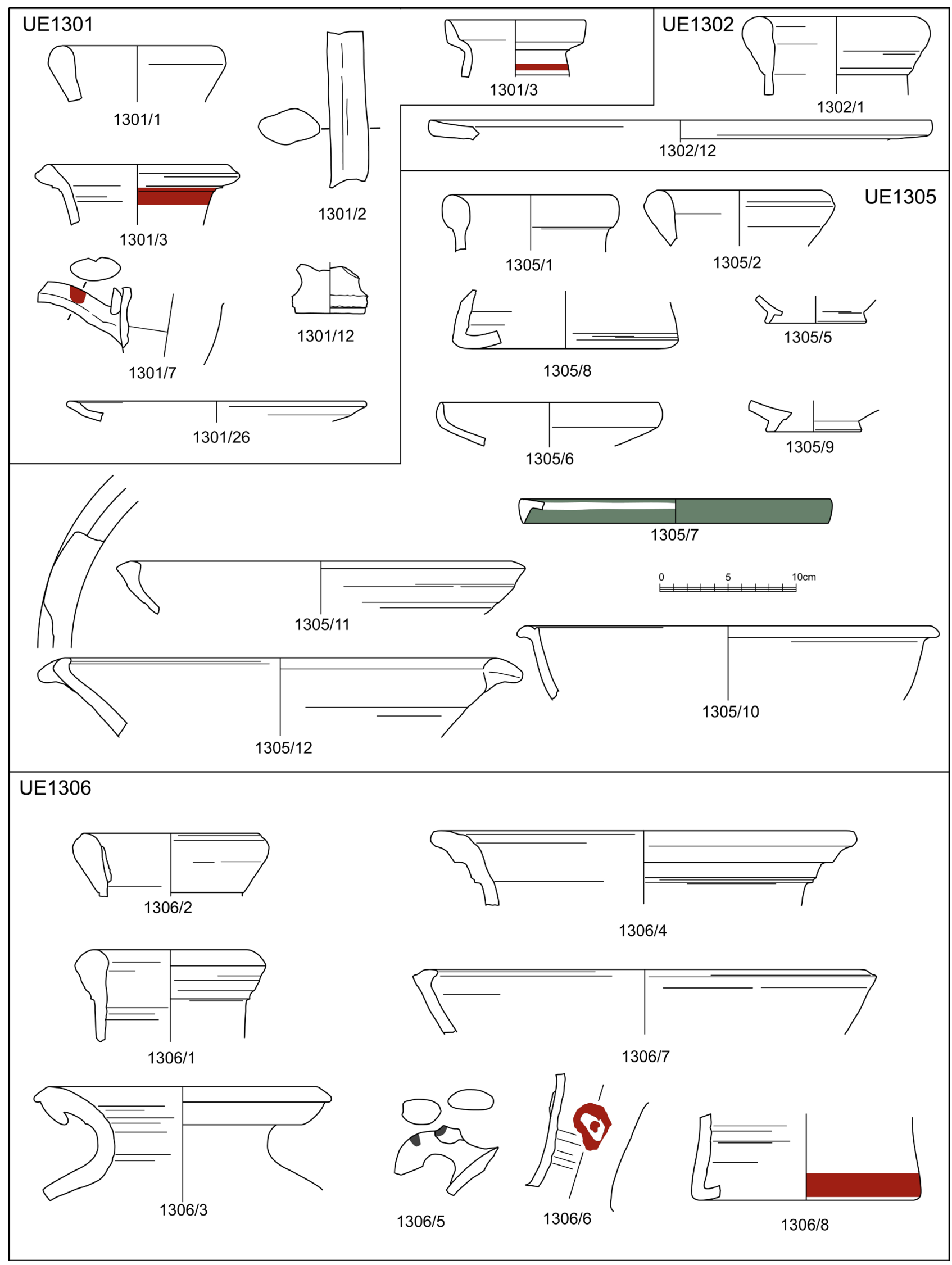

Figura 7. Materiales de las UEs1301, 2, 5 y 6.

Revista Atlántica-Mediterránea de Prehistoria y Arqueología Social 22, pp. 79-107 Universidad de Cádiz 
(1319/10), borde de pithos fenicio de importación malagueña (1319/11), base rehundida y perfil inferior de jarra eb. mediana con línea de pintura roja (1319/15), base de mortero eb. (1319/18) y fragmento de fondo de copa de Campaniense A con rueda de dientes y hoja de hiedra (1319/19) (Figura 10).

UE.1322 (Figura 8).- base y perfil inferior plato gris eb. L23 (1322/1).

El sector 8400, ya en la zona 8000, proporcionó una interesante secuencia estratigráfica, articulada entre un profundo corte en el substrato rocoso y un potente muro, que discurre entre el siglo IV a.C. y los inicios de la época imperial romana, dejando de lado los horizontes de época medieval superpuestos (Ramon, 2000: 27-32, fig. 17-22).

UE.8422 (Figura 8).- espalda de gran vaso eb. no clasificado con dos líneas de pintura roja $(8422 / 4)$, borde de cuenco convexo gris fenicio (8422/6), perfil de copa ática de barniz negro con palmeta (8422/7), pie de copa ática de barniz negro (8422/8), perfil de cuenco eb. no decorado (8422/12) y perfil de cerámica a mano (8422/13), seguramente también de época fenicia.

UE.8426 (Figura 8).- borde de ánfora T-8131 (8426/1), asa completa de ánfora T-8131/2 (8426/2), asa de ánfora T-8131/2 (8426/3), base y perfil inferior de cuenco eb. carenado con pintura roja (8426/4), borde de cuenco eb. L31 (= Guerrero ,1999, fig. 5 tipo A.1.I.3.) con pintura negra en el borde (8426/5), borde de cuenco eb. sin pintura seguramente de tipo carenado (8426/6), borde de cuenco eb. sin pintura, abierto no clasificado (8426/7), perfil de cuenco o copa campaniense A antigua o media, no clasificable (8426/8), borde de cuenco de procesamiento eb. sin pintura tipo FE-13/273 (8426/9) y diversos fragmentos de ollas eb. grandes quemadas por uso $(8426 / 10)$. Estrato formado alrededor de mediados del siglo II a.C.

UE.8428 (Figura 8).- borde de ánfora PE-24 (8428/1). Estrato formado alrededor de mediados del siglo II a.C.

UE.8430 (Figura 8).- borde de jarra Eb76 con línea de pintura roja (8430/1) y borde de cuenco eb. Con círculos concéntricos de pintura roja $(8430 / 2)$. Estrato formado en la segunda mitad del siglo III a.C.

UE.8431 (Figura 8).- borde de cuenco eb. con pintura roja (8431/1), borde de mortero eb. $(8431 / 2)$, pico, parte superior y perfil de lucerna ática $(8431 / 3)$ (Figura 10) y parte inferior de te- rracota eb. (8431/4) (Figura 10). Estrato formado en la misma época que el anterior.

UE.8433 (Figura 8).- base de ánfora PE no clasificada, abotonada (8433/1), cuello y espalda de jarra eb. con estrías, no clasificable (8433/2), cuerpo de gran jarra eb. con líneas horizontales de pintura roja (8433/3), cuerpo de gran jarra eb. Con líneas horizontales de pintura roja $(8433 / 4)$, borde moldurado y perfil de plato? eb. sin decoración $(8433 / 5)$, borde engrosado de cuenco convexo eb. sin decoración $(8433 / 6)$. Estrato formado alrededor de la primera mitad o mediados del siglo III a.C.

UE.8437 (Figura 9).- borde y de cuerpo ánfora Vandermersch MGS II / Gassner 7 (8437/1), espalda y carena de ánfora fenicia de fabricación ibicenca T-10121 (8437/2), borde de cuenco gris fenicio también ebusitano (8437/3), cuenco completo, con algunas lagunas, convexo eb. sin decoración pero conservando abundante pigmento rojo en todo su interior (8433/4). Estrato formado en el siglo IV o inicios del III a.C.

UE.8438 (Figura 9).- asa y espalda jarro/a eb. sin decoración, no clasificable (8438/1), fragmento de punta de ánfora del grupo Cartago-Túnez, con línea de pintura roja (8438/2). Cronología probablemente como el anterior.

\section{Estudio de los materiales}

Antes de entrar en materia, una simple cita a la pequeña serie de fragmentos vasculares de época fenicia, que no se ha querido dejar de incluir, para no desligarla completamente del conjunto de cerámicas preimperiales del castillo de Ibiza, aunque algunas piezas ya fueron publicadas y consideradas hace años (Ramon, 1994b: 352-353, fig. 11). Cabe recordar que una importante secuencia fenicia in situ en la zona del Patio de Armas y Casa del Gobernador del castillo ha sido hallada, mucho más recientemente, y publicada (Ramon y Esquembre, 2017). En cambio, todos los fragmentos de época fenicia de la campaña 1988-1989, fechables entre $c .600$ y 530 a.C., aparecieron en posición residual en estratos de época púnica, imperial romana y vándala. Dejando de lado otros elementos vasculares de esta época, generalmente cuerpos de ánforas, son los siguientes: platos con engobe rojo de fabricación ebusitana (1205/209, 1205/210) (Figura 5), cuencos convexos grises ebusitanos $(1205 / 212,8437 / 3)$ (Figuras 4 y 8) y de producción malagueña $(1205 / 211,8422 / 6)$ 
Materiales cerámicos de los horizontes púnicos del Castillo de Ibiza, excavaciones de 1988-1989

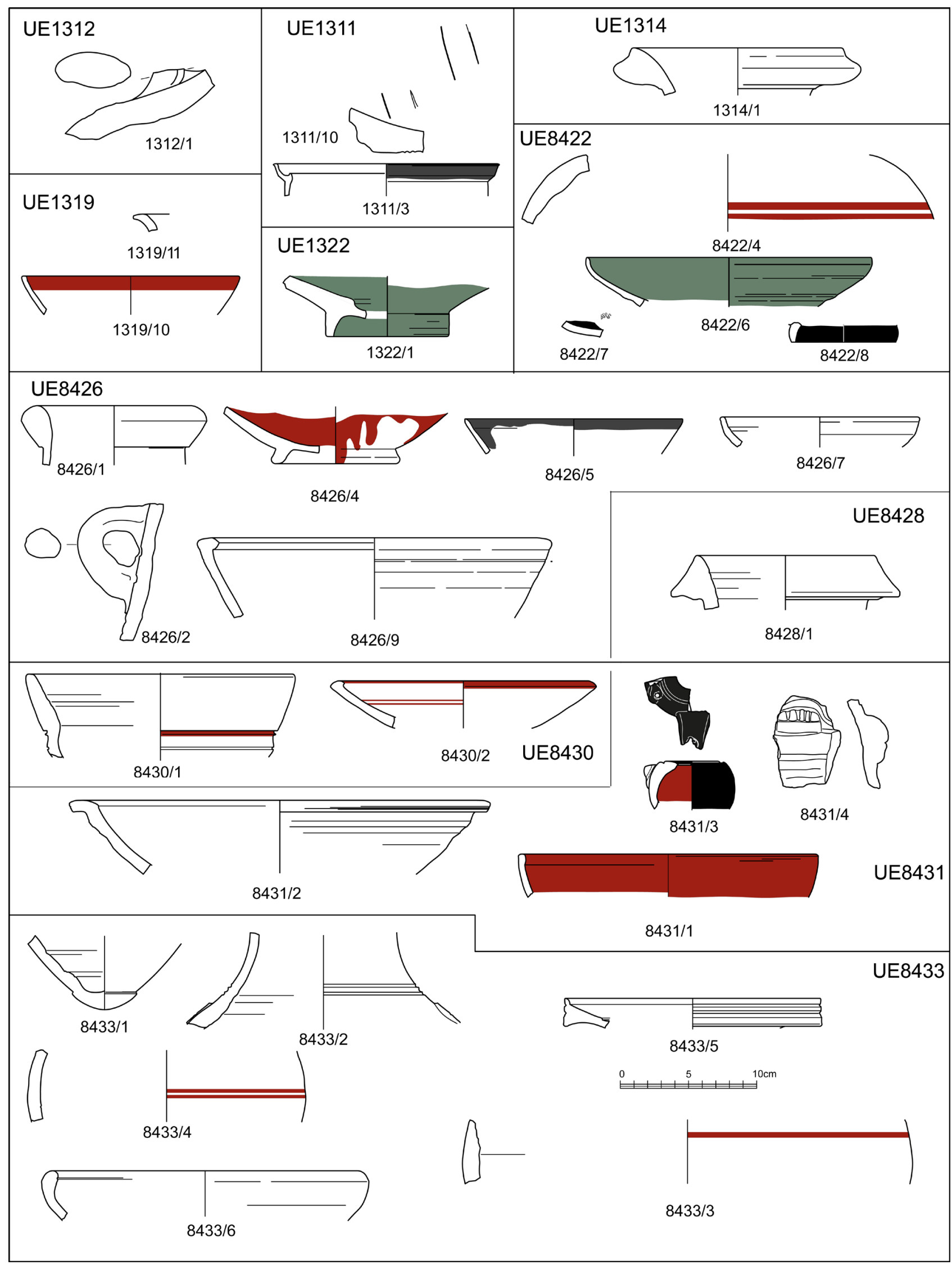

Figura 8. Materiales de las UEs1311, 12, 14, 19, 21, 8422, 26, 28, 30, 31 y 33.

Revista Atlántica-Mediterránea de Prehistoria y Arqueología Social 22, pp. 79-107 Universidad de Cádiz 


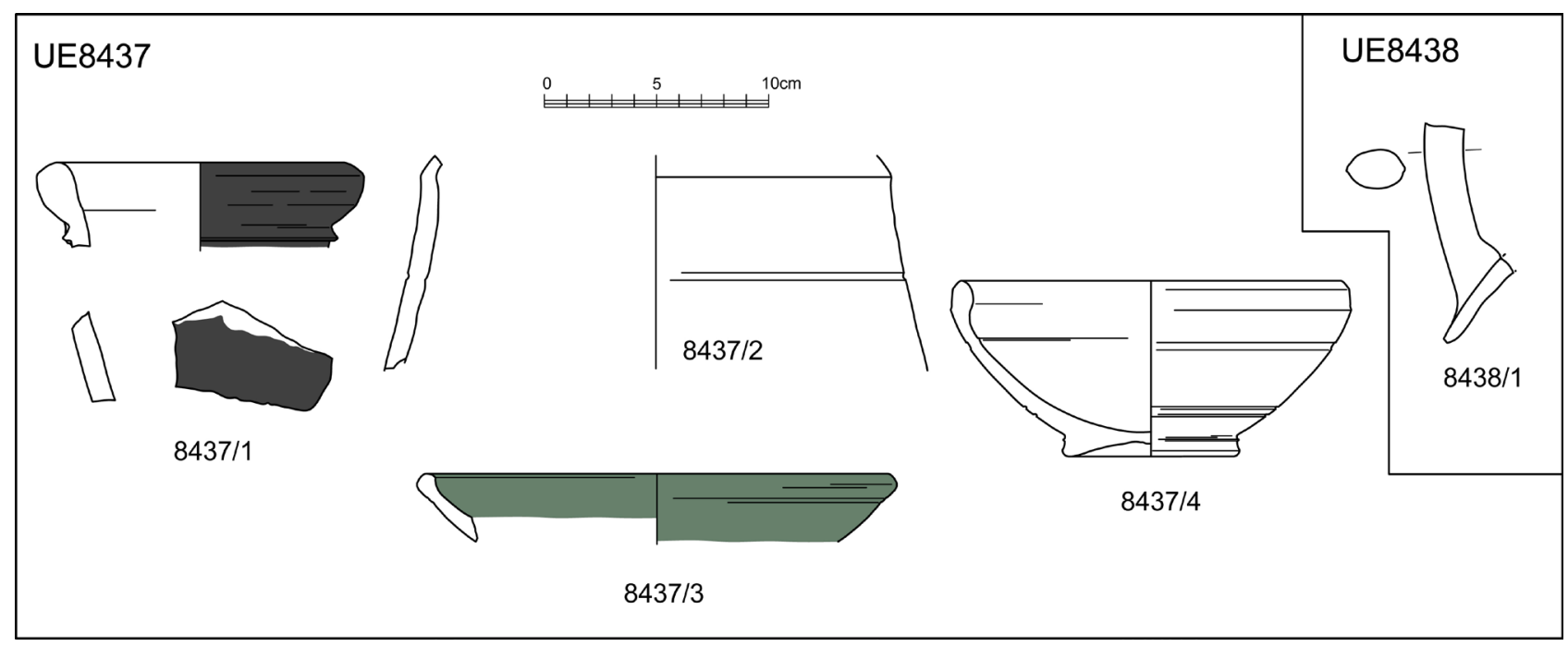

Figura 9. Materiales de las UEs 8437 y 38.

(Figuras 5 y 8), cuenco carenado ebusitano con engobe rojo (1206/5) (Figura 5), pithos de importación (1319/2) (Figura 8), ánfora T-10121 ebusitana $(8437 / 2)$ (Figura 9).

\section{1. Ánforas}

La presencia de ánforas ebusitanas T-8121, cuya cronología se halla bien establecida en los dos primeros y, sobre todo, en el tercio central del siglo III a.C., es significativa en el horizonte púnico de 1988-1989 (1211/1, 1305/1, 1218/1-3, $1218 / 8)$, contando con seis individuos. Por razones de puro azar se hallan todos ellos descontextualizados. En cambio, sólo un individuo es asignable al T-8131 (8426/1), pero esta presencia, casi irrelevante, no puede ser debida a otra cosa que la parquedad de materiales del último cuarto / tercio del siglo III a.C. entre los conjuntos analizados. Más relevante, de nuevo es la presencia del tipo T-8132, con ocho individuos $(1211 / 2-5,1305 / 2$, 1306/1-2, 1301/1). Todos ellos de formato clásico, tienen como es lógico, presencia significativa en los horizontes del pleno siglo II a.C. Sin dejar las ánforas eb. un fragmento correspondiente a la punta, que es abotonada (8433/1), aunque no se halla aparentemente clasificado, ni puede establecerse la forma global del ánfora correspondiente, por la factura de lo conservado podría ser una versión local de ánfora púnica cilíndrica centro-mediterránea, en la onda de modelos como el T-4215 $\mathrm{u}$ otros posteriores o, incluso de algunos tipos del SG-6120, sin agotar el repertorio. En todo caso, su cronología es siglo IV o III a.C., no sólo por los posibles prototipos señalados, sino también por la cronología de la UE a la cual pertenece. Por otra parte, dos bordes son atribuibles al tipo PE-22 $(1212 / 1,1314 / 1)$, de los siglos IV-III a.C., y otro al PE-24 (8428/1), de pleno siglo II a.C. (Ramon, 1981, 1991).

En el grupo de ánforas de importación, por ser el primer hallazgo de esta clase en Ibiza, destaca un individuo del tipo MGS II de Vandermersch (1994: 65-69), equivalente a "Randform" 7 (Gassner et al., 2014, 242-243, fig. 27) (8437/1). Tiene pasta anaranjada con desgrasante grueso y una espesa capa exterior negruzca, que parece recubrir todo el recipiente que, probablemente, fue fabricado en la colonia griega de Poseidonia, entre el último cuarto del siglo $\mathrm{V}$ y el primero del IV a.C. Se trata de un producto con una cierta difusión en ambientes púnicos del Mediterráneo central (Bechtold, 2018: 6, fig. 3 n.o 1), pero apenas conocido más al Oeste.

En cuanto a ánforas itálicas, a nivel de formas, se registra solamente un asa (1301/2), siendo el resto del tipo greco-itálico tardío y pasta férrica (1211/11, 13-14), a juzgar por los fragmentos de perfiles $y$, además, otra de pasta muy fina volcánica y sin duda antigua y (1211/15), junto con otra asa de las mismas características, propias del siglo III a.C. (1305/4, estrato que aporta además dos muestras de ánforas greco-itálicas con pasta férrica) y finalmente, la espalda de una greco-itálica tardía (1312/1).

En cuanto a ánforas africanas, se registra un pivote (1211/9) atribuido a uno de los tipos del G-7400, sin posibilidad de mayor precisión así como cuatro fragmentos de ánfora púnica de la 

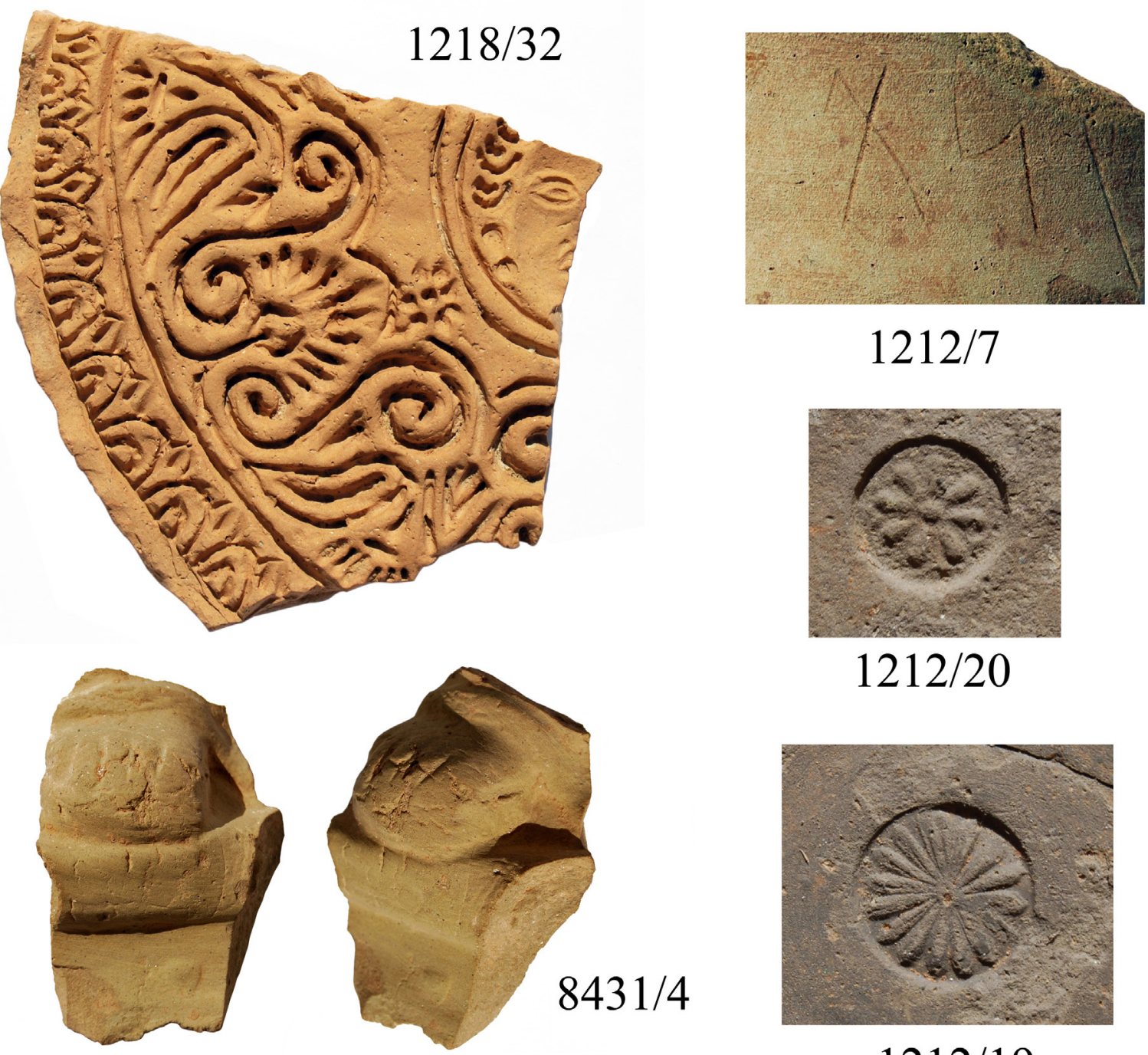

$1212 / 20$
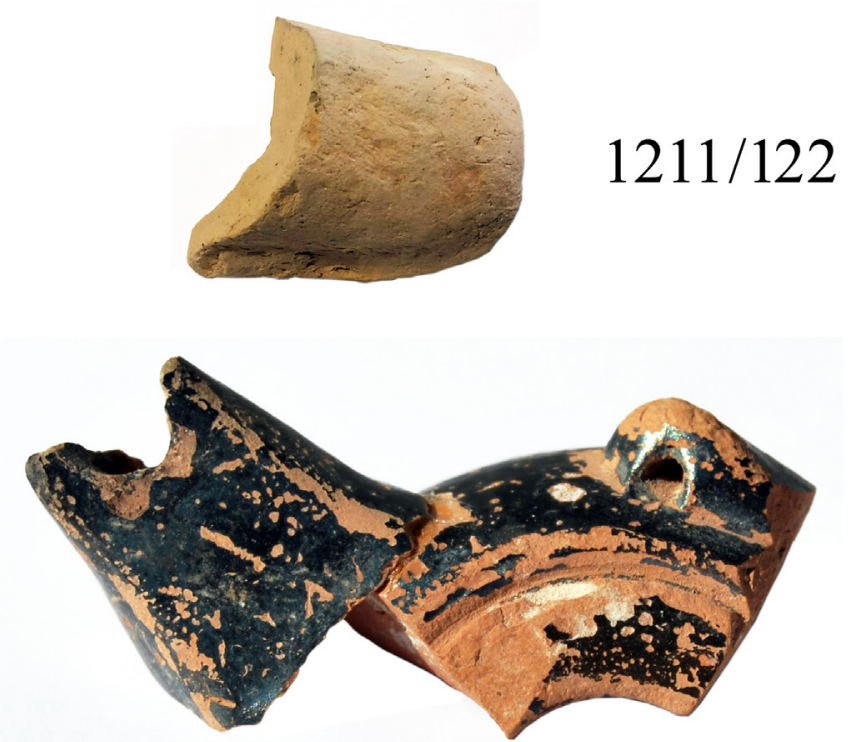

$8431 / 3$
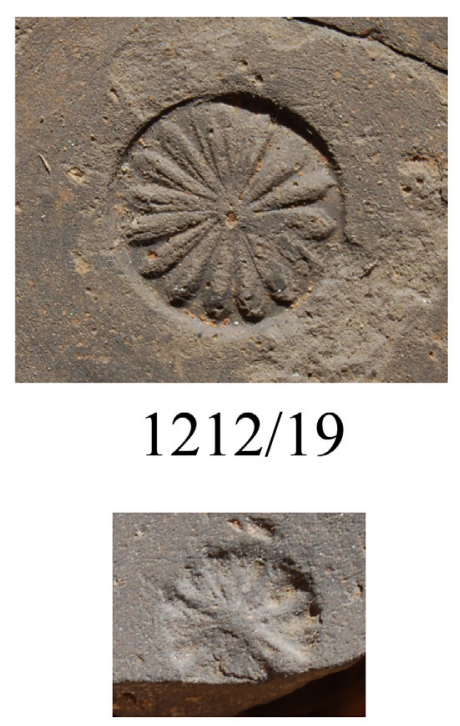

$1212 / 21$

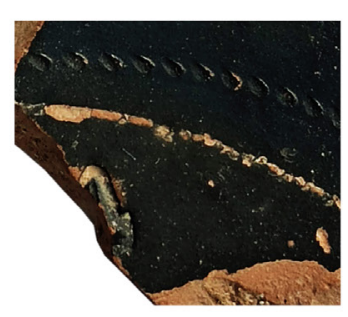

$1319 / 19$

Figura 10. Selección de materiales de diversas UEs.

Revista Atlántica-Mediterránea de Prehistoria y Arqueología Social 22, pp. 79-107 
misma procedencia, de la UE1305, no clasificables. Destaca un cuello completo T-7311 (Ramon, 1995, fig. 174) (1306/3), tipo de ánfora fabricada en el África tardo-púnica de la primera mitad del siglo II a.C. y que en Ibiza está relativamente bien documentado (Ramon, 1981b, lám. III, 10-12; 1995 n.음 226-228; 2008, fig. 1 no 1 ). Finalmente, existe un fragmento demasiado pequeño para su clasificación, de cuerpo (1211/12) de ánfora africana, con una línea de pintura roja $(8438 / 2)$, con un tipo de pasta que concuerda con la cronología de siglo V-IV a.C. de la UE de donde procede.

Únicamente se documenta, y casi a nivel testimonial, un fragmento de cuerpo de ánfora ibérica (1211/92). Cabe recordar que la importación en la isla de ánforas de esta procedencia, más que significativa en los siglos $V$ y IV a.C., decae considerablemente a partir del siglo III avanzado y, más aún, a lo largo del II a.C. (Ramon, 1998: 171).

\subsection{Contenedores medianos y pequeños}

Jarras eb. tipo RA-91/69 (Ramon, 2012c: 591, fig. 8): no cabe sino una simple referencia a tres fragmentos que corresponden a jarras de este tipo $(1212 / 4,1212 / 6,1218 / 5)$, puesto que su posición es residual. Se trata de jarras de formato más bien grande, sin cuello y asas de arranques en horizontal, generalmente pintadas, cuya cronología se mueve entre los últimos decenios del siglo $\mathrm{V}$ y los primeros del IV a.C.

Jarras Eb76 y Eb77: tienen una presencia más que significativa en el conjunto estudiado $(1212 / 5$, $1211 / 18,21,30,45,46,1305 / 8,1306 / 8,1319 / 5$, descontando que muchos fragmentos de cuerpo, pintados, se han podido identificar también con este tipo) Se trata de dos tipos, muy emparentados entre sí, hasta el punto que no son siempre fáciles de distinguir, en especial tratándose de elementos fragmentarios. Hoy por hoy, son modelos relativamente estudiados (Ramon, 1985, 2012b: 588), cuya cronología es segunda mitad del siglo III a.C. (sin descartar un comienzo anterior) hasta la primera mitad del siglo II a.C., cuando empiezan a desaparecer. Los hallazgos del castillo de Ibiza confirman una vez más la importancia que tuvo esta forma en el lapso temporal citado.

Jarras tipo Eb69: (1211/22-25, 1305/14?, 1301/3, 1218/7): Son jarras biansadas, de cuello acilíndrado y borde triangular, con una presencia moderada en los horizontes del castillo de Ibiza. Han sido repetidamente estudiadas (en último lu- gar, cf. Ramon, 2012b: 603; Sintes y Ramon, 2019: 24-25). Algunos de los bordes documentados, con la su cara superior poco inclinada (1211/23 y 1211/24), corresponden claramente a la morfología propia del siglo III a.C. según atestiguan conjuntos cerrados como HX-1, FE-13, horizontes contemporáneos de na Guardis y, más recientemente, la iglesia de Santa Eulàlia d'Alaior (Sintes y Ramon, 2019: 24-25, fig. 4 y 6). Otros individuos (1211/22 y 1211/25), con un borde mucho más inclinado, pertenecen claramente del siglo II a.C., bien entrado, cuando ofrecen, mucho más a menudo que en el siglo III, motivos pintados lineales y de otro tipo, con técnica bicroma $(1211 / 60)$ en muchas ocasiones.

Jarras eb. tipo C2/15 (Ramon, 1997: 41-42): se trata de un modelo definido a partir de un ejemplar del pecio Cabrera 2 y corresponde a jarras biansadas de cuello moderadamente largo, generalmente aristado o carenado, de formato mediano, aunque su tamaño absoluto varía mucho, como se observa también entre los hallazgos del castillo de Ibiza (1212/2, 1212/2, 1211/19, 1218/6). Este modelo parece ser una evolución a partir de tipos del siglo V-IV a.C., como sobre todo el Eb64, adquiriendo sin embargo personalidad propia, desde mediados del siglo IV a.C. (tipo AE-20/I-109- Ramon, 1990-1991, fig. 3). Al menos en su etapa más antigua, anterior a los últimos decenios del III a.C., se hallan generalmente (o frecuentemente) pintadas con motivos, sobre todo lineales, monócromos, especialmente rojos, por ej., en Alorda Park, fase 2 (Asensio ,2019, fig. Alorda-11 n.o 23) y 3A (Asensio, 2011, fig. 7 n. 6). En cambio, en FE-13, que las produjo de modo sustancial (Ramon 1997, fig. 26-27) ninguna lleva esta decoración.

Hydrias eb. tipo Al/145 (Ramon, 2012b: 587) (1211/37, 1218/14) tipo B.1.VII.1. (Guerrero, 1999, fig. 63, 2). Se trata de vasos cerrados de formato mediano, cuello en general aristado, borde exvasado y, con el distintivo especial: asas con empalmes en horizontal. La mayoría de las pocas que se conocen, por ahora, llevan motivos pintados monócromos. Hecha abstracción de las asas, tienen un evidente emparentamiento formal con las jarras FE-13/139 (Ramon, 1997: 39). Destaca una pieza completa de la necrópolis alicantina de l'Albufereta, que procede del loculus F-145 (Verdú, 2015: 89, 150-151, fig. 3.86, 3.90) -y de ahí la clasificación $\mathrm{Al} / 145$, que proponemos provisionalmente-, pero sin asociación con otros materiales, excepto huesos, armas y otras cerámicas, que 
lamentablemente no se recogieron. Por tanto, su contexto es el general de la necrópolis y, en este caso, sin duda, el siglo III a.C. pleno o final. En la fase $3 \mathrm{~A}$ del asentamiento ibérico de Alorda Park parece también documentarse este tipo, avanzado el siglo III a.C., (Asensio 2019, fig. Alorda-18, n.o 1).

Askoi eb.: Se trata de jarros con cuello moderadamente largo y estrecho, desplazado a uno de los extremos de la espalda con proyección un tanto oblicua, cuerpo achatado, con base rehundida y diámetro máximo en la parte alta del cuerpo, frecuentemente tienen decoración pintada a base de líneas horizontales, meandros, siendo muy característicos los ojos en el cuello. En realidad, se trata de un tipo de vaso no excesivamente conocido, que en Ibiza aparece ya en el último tercio del siglo V a.C. (pozo SJ-90, inédito), documentándose también en el IV a.C. (Ramon, 2011, fig. 15 AE-36/II-22), en el III a.C. (Ramon, 1994a, fig. 7-8; 1997, fig. 17) y prolongándose su producción, al menos, hasta el siglo II a.C.. La falta de un número suficiente de vasos completos de este tipo complica su seriación tipológica. A pesar de ello y con los datos disponibles, puede afirmarse que el individuos (1212/9) es un modelo próximo al del taller AE-36, antes citado, del siglo IV o III a.C., mientras que por sus características, el resto (1211/32, $1211 / 43,1211 / 50,1211 / 51,1211 / 58,1211 / 59$, $1211 / 68,1211 / 69,1211 / 72,1211 / 85,1211 / 118$, 1211/, 1306/6, 1301/7, 1218/12,1218/13), está compuesto por piezas más tardías, del siglo III a.C. avanzado y, especialmente, del siglo II a.C.

En este sentido, cabe recordar que del Turó de ses Beies, en Mallorca, procede un verdadero arquetipo del siglo II a.C. (Camps y Vallespir, 1998, fig. 77, 8/4), con el cuerpo cónico, rectilíneo y fuerte ruptura de curva, espalda baja con depresión superior, asa con acanalación en cuña y aplique debajo del borde y tratamiento de pintura bicroma, lineal en el cuerpo, meandros en la espala y ojos en negro en el cuello. Corresponden al tipo B.1.VI.1 de Guerrero (1999, fig. 62). Se registraron algunas piezas muy fragmentarias de este tipo en el nivel II del yacimiento submarino denominado "fondeadero N de na Guardis" (Guerrero, 1984 fig. 23), con al menos otros tres ejemplares de este mismo tipo completos (Cerdá, 1980, no 172-174). Otra pieza completa en una colección particular de Mallorca procedería de Ibiza (Cerdá, 1980, nº 171). Recientemente, un ejemplar completo ha sido hallado en el islote de na Galera y divulgado a través de internet, que es básicamente como el del
Turó de ses Beies, pero sin aplique y con decoración monocroma roja.

En suma, cabe destacar la presencia porcentual y absoluta, más que remarcable, de askoi eb. en el conjunto vascular del castillo de Ibiza estudiado.

Otros contenedores eb. medianos y pequeños: borde triangular muy exvasado (1212/6) de jarrito indeterminado, sin excluir que se trate también de un askos, parte baja del perfil de jarro/a eb. de tipo no precisable por fragmentación, conserva tres líneas de pintura roja (1212/10), jarros de cuello hinchado con acanalación no clasificados (1211/20, 1211/28), finalmente, el individuo $(1211 / 56)$ corresponde a una base rehundida no clasificable.

Jarritos Eb13c: 1211/42 y 49, se documentan al menos dos individuos. Tipo bien estudiado, que pertenece al pleno siglo II a.C. (cf. en último lugar, Ramon y Pons, 2017: 98).

Jarrito Eb13a-b o Eb23c (1218/9) (cf. en último lugar, Ramon y Pons, 2017: 97-97; Sintes y Ramon, 2019: 25-26), último tercio del siglo III a.C.

Oenocoe eb. de boca trilobulada (1218/10). A pesar de ser abundantes en la producción vascular ebusitana los jarros de boca trilobulada, denominados oenochoes, habitualmente, el fragmento registrado, según el perfil concreto del cuello, no corresponde con ninguno de los tipos conocidos, sobre todo los denominados Eb1 y Eb2, aunque su arquitectura completa es imposible de precisar. No lleva (o no conserva) decoración pintada y debe fecharse, con toda probabilidad, en el siglo IV o III a.C.

Jarrito Eb23c (1218/11) Se trata de un modelo, de los últimos decenios del siglo III a.C., definido recientemente, con una puesta al día (Sintes y Ramon, 2019: 25-26), después, cabe añadir otro individuos del poblado ibérico de Alorda Park, fase 3B (Asensio, 2019, fig. Alorda-27, n.o 38).

Jarras Eb73a (Fernández y Costa, 1998, fig. 26) = tipo B.I.II.2. (Guerrero, 1999, fig. 46-50), un sólo individuo es claramente identificable entre los materiales del castillo de Ibiza (1211/26), con una línea de pintura roja, que pertenece claramente al siglo II a.C.

Grandes vasos cerrados eb. no clasificados: $(1211 / 87,1211 / 88)$. Se caracterizan por una carenación muy acusada y un cuerpo cónico, sin decoración, aunque lo conservado no permite otras precisiones. No podría incluso descartarse invirtiendo los dibujos que se tratara de grandes cuencos profundos. 
Vaso eb. cerrado de forma indeterminada: se caracteriza, hecho excepcional, por tener al menos una doble asa superpuesta (1306/5), conservando trazos de pintura negruzca. Se trata de una forma completamente inédita cuya arquitectura global, por ahora, es desconocida, sin poderse señalar paralelos de ninguna clase.

Contenedores medianos y pequeños de importación: a producciones africanas pertenecen algunas piezas, como la base de un pequeño jarrito que, seguramente, corresponde a una forma de cuello cilíndrico, con única asa sobre el borde $(1211 / 57)$, del tipo 521c de Lancel $(1987$, pl. 18) = Vegas, 1999: 164-165, abb. 63c, f.29.3 = Guerrero, 1999, fig. 71 n.o 3. Existen al menos tres ejemplos completos en la ya citada necrópolis de l'Albufereta (Verdú, 2015: 152-153, fig. 3.91, 3.93), en este caso sin contexto conocido, pero siempre anterior al final del siglo III a.C. Se trata de un modelo (o modelos emparentados) que sufrieron una amplia exportación y era conocido con anterioridad en Ibiza (Cerdá, 1980, no 139; Fernández ,1992, fig. 75 no 287). Otros contenedores africanos del castillo no son clasificables debido a su estado de conservación $(1212 / 15,1211 / 90)$. Un fragmento, de pasta también claramente africana (1211/29), no ha podido relacionarse con ninguna forma vascular concreta. Por otra parte, existe la base de un jarrito de producción indeterminada y forma tampoco precisable (1211/91). Cabe mencionar, a continuación, un vaso bicónico ibérico de pasta gris con cono superior nervado (1212/16), variedad precisa de un modelo harto conocido, que aparece en el último tercio del siglo III a.C perdurando a lo largo del II a.C.

$\mathrm{Y}$, finalmente, un ungüentario globular (1212/18), del cual se conservan dos fragmentos correspondientes al borde, cuello y espalda, con múltiples líneas rojas horizontales, tipo Cuadrado II = Forti I, entre otras muchas clasificaciones, francamente, poco convincentes ( $c f$. un resumen actualizado de la situación en Verdú, 2015: 163167). Muy abundante en necrópolis como El Cigarralejo y l'Albufereta (Verdú, 2015: 163-167, fig. 3.110 y 3.115 ), igual que en otros muchos cementerios prerromanos del Mediterráneo, excepto, precisamente, en el Puig des Molins, donde todos los numerosos pequeños contenedores de esta categoría, identificados hasta la fecha, pertenecen a modelos más tardíos. Destaca, además, el hecho que la pieza del castillo no pertenece a un contexto funerario. Su cronología más probable es siglo
IV a.C. y su pasta la acerca a producciones africanas, pero la cuestión de su procedencia, por ahora, debe quedar en suspenso.

\subsection{Vajilla}

Vajilla ebusitana decorada con líneas monocromas horizontales, en general rojas: gran cuenco convexo abierto con dos líneas horizontales de pintura roja en el interior $(1211 / 111)$, que recuerda la pieza AE-20/I-136 (Ramon, 1990-1991, fig. 6). Otra pieza corresponde al tipo AE-7/119-6 (Ramon, 2011, fig. 11), pero con la decoración en la cara externa (1218/19) y, finalmente un cuenco convexo, muy abierto, también tiene correspondencia con los productos del taller AE-7 (8430/2). Se trata de formas típicas del último tercio del siglo $\mathrm{V}$ a.C., en el caso de las dos últimas, y del IV a.C., de la primera.

Vajilla ebusitana tratada con pintura por inmersión: cuencos convexos altos, no aristados forma V-1a en la nueva propuesta de J. Pérez (2018, fig. 6) $(1212 / 27,8431 / 1)$, son típicos del siglo III a.C., bien documentados en AR-33/V entre otros muchos conjuntos, como HX-1 (Ramon, 1994a, fig. 9 n. 53 y 10 n.. 54, 2011, fig. 20). Copas L27 (= tipo A.1.I.2.b. Guerrero, 1999, fig. $4 \mathrm{~A}=$ formas IV-1a-b, Pérez, 2018, fig. 5) (1212/24, 25, 1211/102-103), y se consideran versiones ebusitanas de formas de barniz negro, primero del siglo III a.C. y después de la Campaniense A, como ha sido repetidamente estudiado (en último lugar, Ramon, 2012b: 611; Pérez, 2018), puesto que su cronología, además de dicho siglo, cubre también todo el II a.C., prolongándose incluso en el I a.C. cuencos carenados: (1211/97, 99) (en último lugar, Ramon, 2012b: 609; Pérez, 2018, forma V-1b, fig. 6) son típicos del siglo II a.C., a pesar de lo cual, su fabricación, y evidentemente su uso, se prolonga al menos durante la primera mitad del siglo I a.C., como demuestran estratos inéditos del Cap des Llibrell. Platos de pescado L23 (1212/26, 1211/104-105, 1218/18) (= Guerrero, 1999, fig. 12 y 12a tipo A.1.II.3. = Pérez, 2018, forma I-2, fig. 2) que son muy típicos con este tratamiento de los siglos III y II a.C. pero difíciles de separar cronológicamente hablando. Cuenco especial con borde triangular muy exvasado (1211/109) que podría ser una versión ebusitana del modelo Campaniense A (o incluso de las producciones del taller de Roses) L28, que en ocasiones adoptan tipos de bordes muy salientes. Copas L31 (8426/5, ¿1305/5?) producciones que 
en Ibiza pertenecen a pleno siglo II a.C., siendo muy típico que la pintura sólo afecte la parte cercana al borde (Ramon, 2012b, núm. 127 =Pérez, 2018, forma III-1, fig. 4). Páteras L55: (1211/106), se trata de platos muy abiertos, con bases anulares más o menos altas y que deben considerarse versiones ebusitanas de la Campaniense A (Morel 1981, F2234a, 2234a, entre otras). Se enmarcan en el tipo A.1.II.5.b (Guerrero, 1999, fig. 15) y Pérez, 2018, forma II-1a, fig. 3 (cf. también Ramon, 2012b, fig. 13 no 119, 120 y 121). En cualquier caso, es importante señalar, porque tiene implicaciones cronológicas, que afectan especialmente la UE1211, que en original, el modelo no aparece antes del 175 a.C. (Sanmartí Grego y Principal, 1998 : 209), fecha que vincula su adopción ibicenca, que desde entonces pasó a fabricarse a gran escala. Cuencos especiales: A.1.II.5.a (Guerrero, 1999, fig. 14) pátera muy abierta que, en versión reducida, recuerda la L55 (1211/107), pequeño cuenco convexo, relativamente abierto (1211/108) recuerda cuencos áticos o derivados occidentales Existen, siempre con la misma clase de pintura, jarritos (1218/16, 1218/17) monoansados del siglo III a.C. (Ramon, 2011, fig. 20 AR-33/V-18).

Vajilla ebusitana en pasta gris: Las copas derivadas de las Outturned rim bowl áticas (1212/19$23,1211 / 98$ ) tienen, sobre todo en la UE1212, una presencia muy relevante, corresponden a la forma V-2a en la nueva clasificación de Pérez (2018, fig. 7). Merece la pena un comentario a la cronología de esta forma, empezando por señalar su ausencia absoluta, tanto en el importante conjunto del taller FE-13, como en los estratos contemporáneos de na Guardis, cosa que podría apuntar a la extinción del modelo ya antes de los últimos decenios del siglo III. De hecho, al menos una buena parte de los motivos estampillados que suelen ofrecer, responde a prototipos comunes más bien en los dos primeros tercios de este siglo. En todo caso, el grupo de cuencos grises de este tipo de la UE.1212 podría fecharse en los cuartos centrales del siglo III aC. A lo dicho en su día sobre este modelo (Ramon, 2012b: 598), puede añadirse el nuevo estudio de la necrópolis alicantina de l'Albufereta, donde está bien representado (Verdú, 2015: 159-160, fig. 3.98, 3.102, 3.103), así como la pubicación de algunas piezas de esta forma del solar 3, avenida España (Duarte, 2016, fig. 27) en un contexto del siglo III a.C., pero poco definido. El resto de vajilla eb. en pasta gris se compone de platos pescado L23 $(1305 / 7,1322 / 1)$ y copas L27 (1211/101) y L28 o forma V-2b de Pérez (2018, fig. 7) (1211/100, con barniz gris de muy buena calidad) y lo dicho antes para estos modelos con baño de pintura vale también ahora.

Vajilla ebusitana de pasta común sin decoración: El individuo (8426/7) adopta la forma L27 pero con carena, otras dos piezas encuentran sus modelos en la producción del taller AE-20, respectivamente del tipo AE-20/I-136 (Ramon, 19901991, fig. 6) (1212/28) y AE-20/I-139 (Ramon, 1990-1991, fig. 6) (1212/30), se trata de piezas del siglo IV a.C., pero que podrían tener continuidad en el III a.C. Otras piezas de vajilla sin tratamiento son: cuenco convexo muy abierto, con borde ligeramente engrosado (1211/115), plato recto y plano, con borde moldurado tipo FE-13/91 = A.1.II.6 (Guerrero 1999, fig. 16, 1-2) = forma II-2 (Pérez, 2018, fig. 3) (1211/116), cuenco convexo abierto (1305/6), plato tipo AR-33/V-8/9 (Ramon, 2011, fig. 19) = Pérez (2018, fig. 2) forma I-4 (1301/26). Destaca, sin embargo, conservando el perfil completo, un cuenco eb. de base indiferenciada por el exterior, rehundida, con borde ranurado, no clasificado, sin decoración, que se denominará provisionalmente tipo C.1218/20 (1218/20); podría ser una versión ibicenca del tipo cartaginés $272 b 1$ de Lancel (1987, pl. 9), existen otros cuencos convexos con borde engrosado al interior (8437/4 y $8433 / 6)$, que tienen paralelos bastante claros en las producciones del denominado taller AE-36 del siglo IV a.C. Cabe mencionar un cuenco eb. convexo y alto tipo AE-20/I-125 (Ramon, 19901991, fig. 5) (1218/21). Finalmente, el fragmento $(8433 / 5)$ parece pertenecer a un plato de inspiración helenística, sobre base anular alta, que puede tener un similar en una tumba colectiva de amplia secuencia localizada en cap Pep des Ferrer (Marí y Graziani, 2013, fig. 5 n.․ㅜ 12).

Vajilla de barniz negro de importación: cerámica ática de barniz negro, del tipo incurved o outturned rim bowl $(8422 / 7,8422 / 8)$. Campaniense A antigua: L23 (= Morel 1981 F1120) (1211/149), L27a-b (= Morel 1981 F2784, 2788) (1211/140142), L28a-b (= Morel 1981 F2612-2614, 26412648, 2654) (1211/143,5, 1211/144, 1211/146), L36 (= Morel 1981 F1312-1314) (1211/148), L48A (= Morel 1981 F3155) (1211/153), L33b (= Morel 1981 F2973-2974, 2985) (1211/147). Es importante en este grupo el fragmento con hoja de hiedra (1319/19). Calena Antigua, píxide Morel 1981 F7510 (1211/150,1), L36 (1211/152).

Cerámica eb. de cocina.- Grandes cuencos 
de procesamiento y morteros: los cuencos tipo FE-13/273 (Ramon, 1997, fig. 46) (1211/112, $1211 / 113,8426 / 9,1306 / 7,1305 / 11,1305 / 12$ ) tienen una presencia notable entre el material estudiado, afecta en este caso únicamente estratos formados en pleno II a.C. Existe también un cuenco tipo AE-20/I-143 (Ramon, 1990-1991, fig. 6) (1212/29).

Morteros eb. tipo AE-20/I-167 (Ramon, 19901991, fig. 8) (1212/31, 1302/12): modelo de larga vigencia, que cubre al menos los dos últimos tercios del siglo IV y los dos primeros del III a.C. Durante los últimos decenios del III a.C., aun no extinguiéndose completamente, empieza a ser sustituido por otros formatos. Morteros eb. tipo FE-13/255 (Ramon, 1997, fig. 43), del último tercio del siglo III aC, con el borde algo colgante (1211/110). Mortero eb. de borde inclinado, con molduras (1211/114), corresponde al tipo C.1.I.1 (Guerrero, 1999, fig. 80, 4), es muy típico del siglo II a.C.

\subsection{Cerámica de cocción/calentamiento}

Cerámica de cocción y calentamiento eb.: existe al menos un fragmento de olla tipo FE-13/308 (Ramon, 1997, fig. 54-55) (1211/131) del último tercio del siglo III a.C. En cuanto a ollas convexas tipo AE-34/II-203 (1211/121, 1212/36), que ya aparecen a finales del siglo III a.C., están atestiguadas entre la producción del taller AE-34 (Ramon, 2011, fig. 23) y son los dos cuartos centrales del II a.C., sin duda, su momento álgido, perdurando, tal vez, en el I a.C. Moderadamente más relevante es la presencia de ollas o cazuelas de borde moldurado $(1211 / 123,1211 / 124,1211 / 126)$ (Guerrero 1999, fig. 94, 1) tipo D.1.I.2., existiendo también tapaderas: (1211/128, 1211/129, 1211/117). Una forma muy abierta se atribuye generalmente a bandejas o soportes (1211/127) (Guerrero, 1999, fig. 94, 2, pero no clasificado), sin que pueda descartarse, sin embargo que sirviera también para procesos de cocción. Finalmente, los jarros de calentamiento, por lo común de boca trilobulada, están representados por un único individuo (1211/130) tipo D.1.IV.1. (Guerrero, 1999, fig. 100, 2).

Cerámica de cocción africana: ollas o cazuelas de borde vertical Vegas f.68.3 (1999: 197, abb. 106) $(1311 / 3,1218 / 27-29)$, mayoritariamente ejecutadas con la técnica denominada red black top ware. Se trata de elementos que conocieron un apreciable grado de exportación fuera de los talleres púnicos del área del actual Túnez, conociéndose actualmente en multitud de asentamientos ibéricos (Asensio, 2001-2002) o en Cartagena (Borredá y Cebrián, 1993, fig. 2 no 7, 8 y 10), sólo a título de ejemplos, puesto que su dispersión es mucho más amplia (Guerrero, 1995: 78-83). En el hipogeo II de la campaña de 1904 en la necrópolis del Puig des Molins aparecieron dos ejemplares pequeño de esta clase (Gómez y Gurrea, 1985).

Otro modelo africano es la cazuela de borde horizontal ancho, con interior escalonado $(1211 / 136)$ igualmente de la red black top ware (Vegas, 1999: 198, f.69, fig. 107 = Guerrero, 1999, fig. 112, 2-4 tipo D.2.II.2.). Se trata también de una forma bien difundida allende la costa africana (Guerrero, 1995: 85-88) que suele fecharse a partir de finales del siglo III a.C., siendo muy abundante en los niveles de destrucción de Cartago y perdurando sin duda a lo largo del II a.C. En Ibiza se conoce una cazuela completa de este tipo también del Puig des Molins, pero sin contexto (Fernández, 1992, fig. 189 n.o 1073).

Los materiales de esta categoría del castillo de Ibiza -que prácticamente igualan en porcentaje la cerámica de cocción ebusitana, junto con otros muchos conjuntos ibicencos de los siglos III-II a.C., aún inéditos- desmienten rotundamente una afirmación, de hecho gratuita, por falta en aquel entonces de verdaderos elementos de juicio, de V. M. Guerrero (1995: 83) sobre la escasa presencia en la isla de cerámica de cocina púnica africana, que lamentablemente ha tenido eco en otros investigadores, derivándose conclusiones faltas de base. No se va a entrar ahora en el tema, pero sí -y aquí estamos de acuerdo con el mencionado investigadorse va a incidir en que su presencia en el Mediterráneo central y en el extremo occidente donde, como se ha dicho, se documenta a menudo, no responde a otra cosa que a un flujo comercial en la misma onda que los bien conocidos transportes anfóricos africanos, entre otros materiales de la misma procedencia.

Cerámica de cocción itálica: se reduce a cazuelas y tapaderas (1218/31) de las mismas, con toda probabilidad. Por una parte, existe el tipo Vegas 14 (1973) (= COM-IT 6c, Bats, 1993: 360) (1211/135, $1218 / 30)$ y, por otra, el COM-IT 6d (1305/10).

\subsection{Cerámica de iluminación}

Se documentan dos lucernas, una de ellas, eb. en pasta gris (1211/55), es una imitación de un 
conocido modelo helenístico. La otra es una pieza ática tipo 25B del Ágora de Atenas (Howland, 1958: 72-4, pl. 10 y 38), fechada entre la segunda mitad del siglo IV y el primer cuarto del siglo III a.C. Cabe recordar que este tipo de elemento de iluminación, muy frecuente en los mobiliarios fúnebres, es escaso en contextos de la vida cotidiana.

\subsection{Varia vascular}

Una base anular, alta y maciza, se halla perforada: 1211/121, corresponde a un género caracterizado por tener un agujero ante coctionem que atraviesa completamente el centro de su fondo, hecho que lo inutiliza como contenedor de líquidos. No se conocen por ahora elementos del todo similares.

Merece un comentario algo más detenido la presencia, sobretodo en la UE1211, de soportes de braseros (1211/84, 1211/39, 1211/38, ¿1305/4?). Estos interesantes elementos han sido hasta la fecha desconocidos en Ibiza debido, sin duda, a la fragmentación de los individuos recuperados que ha complicado hasta la imposibilidad la visión global del tipo. Recientemente, el hallazgo en el yacimiento mallorquín de so n'Espases de una pieza de esta clase (Estarellas et al., 2020), completa, excepto la base, ha arrojado plena luz en torno a su morfología. Se trata de un elemento de gran formato (más de $50 \mathrm{~cm}$ ) de perfil bicónico, con la singularidad de empalmar los conos por su parte más estrecha y con la parte superior completamente abierta. Disponen de asas, tanto de empalmes en vertical como en horizontal, según demuestran piezas de esta clase del depósito aún inédito AE-7/137 (alrededor de mediados o inicios del tercer cuarto del siglo II a.C.) y decoraciones aplicadas, tanto de cordones, como de figuras plásticas. En la pieza del citado yacimiento mallorquín se observan ventanas cuoriformes y circulares abiertas ante coctionem y también la presencia de un friso de ovas, esto último exactamente igual que en el fragmento (1211/84) del castillo de Ibiza. Se trata, con plena evidencia, de versiones púnico-ebusitanas de soportes de braseros griegos tardo-helenísticos, llamados clíbanos, con la particularidad que brasero y soporte eran piezas sueltas, previstas para ser colocadas una encima de otra. Aparte del conjunto citado, en Ibiza existen indicios de su existencia en el solar 34, c. Vía Púnica y en el santuario de es Cuieram, como bien apuntan los editores de la pieza de so n'Es- pases, a lo cual cabe añadir también su presencia en un espacio de ambiente también cultual en can Pis (inédito). Ello aumenta la certidumbre del uso también ritual de estos elementos en la Ibiza tardo-púnica de mediados del siglo II a.C., dando plena razón a los comentarios de José Pérez quien, además, hace un buen y amplio resumen sobre esta clase de piezas (Pérez, 2012: 71-73), eximiéndonos de profundizar por ahora más en el tema.

Thymiateria eb.: cazoleta $(1218 / 23)$ y columna central con arranques de las cazoletas (1301/12). Aunque su atribución es clara, no así su tipología precisa, haciendo inútil profundizar en su comentario.

\subsection{Cerámica no vascular}

Terracotas: de una de ellas se conserva sólo uno de los pies (1211/122) (Figura 5) hecho que dificulta su adscripción exacta, puesto que existen diversas posibilidades. En cambio, la segunda (8431/4), de la cual se conserva parte del pedestal, $\mathrm{y}$ uno de los pies hasta el cual llega un manto, que cubría el resto del cuerpo (Figuras 8 y 10). A juzgar por su tamaño la pieza completa debía tener unas dimensiones notables. Podría tratarse de una representación de los denominados Baal, como el conocido (aunque posterior) Baal de Thinissut, actualmente conservado en el museo del Bardo, aunque también tratarse de una figura femenina, de pie sobre pedestal, de tipo bien conocido en Ibiza (p. ej., Almagro, 1980, lám. XLIX). Igual que la anterior fue hallada en un estrato fechado en pleno siglo II a.C. Una tercera terracota es de sumo interés. Se trata de un molde discoidal (1218/32) (Figura 10), con palmetas que enmarcan un rostro femenino que ocupa el centro de la composición, la primera de esta clase entre los muchos moldes ebusitanos conocidos. No cabe extenderse aquí, puesto que será objeto de un estudio específico.

\section{Valoración}

Los horizontes estudiados del castillo de Ibiza dan contenido a una etapa muy importante de su historia, como es la época púnica. Se sabe actualmente que la primera instalación humana, ex nihilo con toda evidencia, tuvo lugar alrededor del 600 a.C., obra de fenicios. Sin embargo este primer momento pudo tener un final violento antes de acabar el tercer cuarto del siglo VI a.C., como se ha planteado en trabajos recientes (Ramon, 2020) e, 
incluso, sufrir una etapa de abandono. Y, en efecto, los materiales obtenidos en 1988-1989, ahora estudiados, parecen también apuntar en esta dirección ya que presentan un vacío en este momento. Algo parecido, al menos en el registro material de la campaña analizada, parece reflejarse entre $c$. el 150 a.C. y los inicios del Alto imperio, como se verá a continuación.

La UE1212 incluye, por un lado, elementos vasculares relativamente antiguos, eso es, del siglo $\mathrm{V}$ avanzado o ya siglo IV a.C., aunque, por el resto, ningún otro individuo parece posterior al segundo tercio del siglo III a.C. o, como mucho a inicios del último cuarto. En consecuencia, la cronología que se asigna a esta unidad es c. 260-230 a.C.

El momento de formación de la UE1211, superpuesta directamente a la anterior, debe situarse hacia mediados, o inicios del tercer cuarto del siglo II a.C. En realidad, esta UE incluye un significativo número de piezas perfectamente compatibles con la época del taller FE-13, como el mortero (1211/110), el cuenco gris L28 (1211/100), algunas de las jarras Eb77, p. ej. (1211/30, 1211/46), las Eb69 (1211/23, 1211/24), la C2/15 de formato reducido (1211/19) e, incluso anteriores, de los siglos V-IV a.C., como el cuenco con líneas pintadas (1211/111), la hydria (1211/37) o el cuenco gris (1211/98). Más ambiguo es el caso de formas en detalle aún poco conocidas como los jarritos (1211/20 y 1211/8), entre otros. Hecha esta salvedad, la componenda de la UE1211 abarca modelos típicos de la última fase de na Guardis, del taller AE-34 o del momento de formación del depósito de can Vicent d'en Jaume, aunque sin duda es algo anterior.

En esta UE la presencia de vajilla importada de barniz negro es significativa. Domina la campaniense $\mathrm{A}$, mayoritariamente antigua, a juzgar, no sólo por las formas, sino también por la excelente calidad técnica de la mayoría, situándose entre $c$. 220 y 180 a.C. (Principal y Ribera ,2013: 113-114). Al menos, dos individuos corresponden a la llamada Calena Antigua, que globalmente se fecha entre 200-130/120 a.C. (Principal y Ribera, 2013: 87). Sin embargo, modelos como la píxide Morel F7510 ofrecen una presencia significativa en los horizontes de la última época de Cartago (Bechtold, 2007: 8, fig. 3 no 14 a, b y 4 no 2,), es decir, con el claro ante quem del 146 a.C. En cualquiera de los casos, la grafía de la inscripción sobre el vaso 1212/7, cuya atribución a la UE1211 y no a la UE1212 según registro de campo, ya hemos señalado, apunta también a esta cronología no anterior a mediados del siglo II a.C.

Menos evidente, en cambio, resulta la cronología inicial de las cazuelas itálicas Vegas (1973) tipo 14. El barco denominado Escombreras 1 transportaba este modelo en una fecha que se estima hacia el 150 o mediados del siglo II a.C. (Principal y Ribera, 2013: 88-90; Ribera, 2013: 459), mientras que otras publicaciones sitúan su aparición incluso, en el segundo cuarto (Díaz, 2000: 223) e, incluso, alrededor del 200 a.C. en la cisterna dels Estinclells (Asensio, 2011, fig. 9 n.o 9). Por otro lado, llama la atención su ausencia en un importante depósito pompeyano recientemente dado a conocer (Bustamante-Álvarez et al., 2020) y datado hacia mediados del siglo II a.C.

Así pues, el panorama de las UEs 1211 -que insistamos una vez más, incorpora un conjunto cerámico fabricado a partir del 225-, 1305, 1306, 8426 y 8428 , incluida una serie de materiales identificados en estratos alterados de la zona 1000 del castillo de Ibiza, apunta a un momento final de formación alrededor del 150 o en los primeros años del 3r cuarto del siglo II a.C. Es, en realidad, un repertorio que recuerda de cerca los horizontes inmediatamente anteriores a la destrucción de Cartago (146 a.C.); incluso el fragmento de Campaniense A con hoja de hiedra (1319/19), sin duda uno de los más modernos del repertorio estudiado, es un tipo decorativo evolucionado, pero ya bien representado en los momentos finales de la metrópolis norteafricana (Sanmartí Grego y Principal, 1998, fig. 10). Ignoramos que ocurre en el castillo entre esta fecha y otros horizontes conocidos que incorporan ya TS itálica, es decir, desde la época de Augusto en adelante ¿un momento de decadencia o incluso abandono en la cúspide de la acrópolis de Ibiza? La respuesta es prematura, pero aquí queda el dato objetivo.

Por otra parte, al lado de similitudes, una comparativa entre las UE 1212 y UE 1211, muestra claras diferencias, a pesar de que el volumen de ítems de la segunda triplica al de la primera. Así, por ejemplo, resalta la escasez de cerámica de cocina de la UE1212, y la falta absoluta de vajilla barniz negro de importación, igualmente, se hallan ausentes elementos cerámicos especiales, como lucernas, soportes de braseros u otros modelos vasculares más difíciles de encuadrar. También faltan las monedas en la UE1212, mientras que en la 1211 apareció un grupo de catorce monedas ebusitanas, muy deterioradas, hecho que recuerda algunos escondrijos, también de mediados del si- 
glo II a.C., como 3 (Matamoros, 1989) y 7 (inédito), avenida España, hecho que incide también en lo dicho antes sobre un eventual momento de crisis.

No es, ni mucho menos, cierto, a pesar de lo visto en la UE1212, que en el tercio central del siglo III a.C. Ibiza no recibiera vajilla de barniz negro ( $c f$. Ramon, 1998) puesto que, sin salir de la excavación del Castillo de 1988-1989, la copa 1218/25 viene a confirmar este hecho, en cambio, lo que con toda probabilidad significa es que su porcentaje absoluto, si se compara con el último cuarto del siglo III y muy especialmente con los primeros decenios o mitad del II a.C., con la divulgación mediterránea a gran escala de la Campaniense A, es mucho más bajo. Y, en efecto, la notable presencia de Campaniense $\mathrm{A}$, junto con un número, en este caso menor, de Calena Antigua en la UE1211 lo demuestra rotundamente, ya que prácticamente iguala en número la vajilla ebusitana.

En los estratos de los siglos III y II a.C. estudiados, especialmente las UE1212 y 1211, llama también la atención la abundancia de askoi de fabricación ebusitana. Este tipo de jarro, un perfecto desconocido en las necrópolis ibicencas, se documenta en el pozo HX-1, en el siglo III a.C., pero en cambio no existe en en el depósito de can Vicent d'en Jaume, del tercer cuarto del siglo II a.C., mientras que en niveles, también de la segunda mitad del siglo II a.C., del edificio A de ses Païsses de Cala d'Hort (inéditos) tampoco se manifiesta su presencia. En cambio, en este momento avanzado de la segunda centuria, al menos en can Vicent d'en Jaume, los panoramas vasculares aparecen dominados por jarras Eb69 y Eb73, como ocurre en cierto modo en na Guardis. Otros vasos, que ya se ha dicho son muy abundantes en el castillo, como las jarras Eb76/77, C2/15, igualmente son escasas en los otros conjuntos comentados. Sin embargo ello puede ser debido a una mayor antigüedad, aún dentro del siglo II a.C. de la facies observada en el castillo. Cabe remarcar también el relativo equilibrio, con ligera preponderancia de la primera, entre vajilla ebusitana con baño de pintura y vajilla gris. En cambio, llama la atención la presencia nula en el castillo de jarras de tamaño medio de los tipos Eb70 y Eb72 cuya producción se centra precisamente entre los últimos decenios del siglo III y los primeros del II a.C.

Al margen de la vajilla, ya comentada, en cuanto a importaciones, los materiales del castillo de Ibiza del siglo III y primera mitad del II a.C. reflejan también un panorama conocido de antemano en la isla, donde las producciones itálicas, tanto anfóricas como de las otras categorías descritas, conviven con las africanas, primero en minoría, pero poco a poco ganando terreno hasta imponerse finalmente, a partir de la segunda mitad de la segunda centuria. Junto con ellas algunas producciones ibéricas que aparecen normalmente, pero en cantidades mucho más pequeñas. Cabe destacar también en esta fase el poco peso (nulo en el castillo de Ibiza) de las importaciones de la zona del estrecho de Gibraltar.

Ya se ha remarcado la notable presencia en el castillo de cerámica de cocción africana y se ha rechazado la creencia de su parca presencia en la isla. De todos modos, y a la espera del estudio y publicación de otros conjuntos, puede avanzarse que en la ciudad y alrededores ésta, frente a la ebusitana, adquiere un valor porcentual más alto que en lugares alejados del mundo rural.

Es lástima que la secuencia orgánica, bastante amplia, que arranca del siglo IV a.C., del sector 8400 , registre tan pocos materiales. Estos, sin embargo, ilustran algo el repertorio vascular de este momento $y$, sin duda de la primera mitad del siglo III a.C. (UE8433). En este contexto se observa además la presencia de cerámica ática de barniz negro (sobre la cual en Ibiza, en último lugar, Ramon y Hermanns, 2012) y de ánforas antes desconocidas en la isla (Ramon, 2004), como la MGS-II de la UE8437.

Si se hace salvedad del interesante molde con rostro femenino central $(1218 / 32)$, que podría ser del siglo III, aunque también del II a.C., todos los elementos que, de un modo u otro, pudieron tener relación con actividad cultual, proceden de estratos del siglo II a.C. En este contexto, a los fragmentos de terracotas, cabe añadir la presencia de thymiateria, y de soportes de brasero, sobre cuyo uso ritual ya se ha hablado antes. Existió, por tanto, actividad de culto en la zona del castillo de Ibi$\mathrm{za}$, sin que por ahora pueda afirmarse si se trató de verdaderos templos o más bien de cultos en ámbito doméstico.

A otro nivel, se observa un relativo equilibrio porcentual entre categorías funcionales en los conjuntos de los siglos III y II a.C. analizados. Y, finalmente, puede contestarse en sentido afirmativo la pregunta planteada a principio: en su conjunto, la componenda vascular del castillo de Ibiza es similar a la de otros ambientes insulares, incluso alejados de la ciudad, pero ello sólo en lo general, quedando por afinar aún otras muchas cuestiones. 


\section{Bibliografía}

ALMAGRO GORBEA, María J. 1980: Corpus de las terracotas de Ibiza. Bibliotheca Praehistórica Hispana, XVI. CSIC. Madrid.

ASENSIO I VILARÓ, David. 2001-2002: “Cerámicas de cocina cartaginesas en contextos ibéricos de la costa catalana". Estudios orientales, 5-6, pp. 305-317.

ASENSIO I VILARÓ, David. 2011: “La presència de ceràmiques púniques ebusitanes al nordest peninsular (segles V-III a.C.): impacte econòmic i social de les relacions comercials entre l'Eivissa púnica i els íbers del nord". XXV Jornadas de arqueología fenicio-púnica, TMAEF, 66, pp. 223-254.

ASENSIO I VILARÓ, David. 2019: Economia i societat dels pobles ibèrics de l'àrea catalana a través de l'estudi dels conjunts ceràmics (segles VI-II a.C.). Tesis doctoral inédita. Universidad de Barcelona.

BATS, Michel. 1993: "Céramique commune italique”. Lattara, 6, pp. 357-362.

BECHTOLD, Babette. 2007: "La classe Byrsa 661 a Cartagine. Nuove evidenze per la tipologia e la cronologia di ceramica calena nella metropoli punica". Carthage Studies, 1, pp. 1-36.

BECHTOLD, Babette. 2010: The Pottery Repertoire from Late 6th-Mid 2nd Century BC Carthage. Observations based on the Bir Messaouda Excavations, Carthage Studies, 4. UGent. Gante.

BECHTOLD, Babette. 2018: "La distribuzione della produzione anforica di Poseidonia/Paestum (V-I sec. a.C.) nell'area di influenza punica (Sicilia, Tunisia, Malta): una revisione dei dati editi e prospettive di ricerca (06-12-2018)". www.facem.at. Consultado el 10 de noviembre de 2020.

BORREDÁ MEJÍAS, Reyes; CEBRIÁN FERNÁNDEZ, Rosario. 1993: “Cerámica de cocina local y de importación en Pl. Hospital - Anfiteatro (Cartagena) s. II a.C. - I d.C. Uso y función". SAGVNTVM: Papeles del Laboratorio de Arqueología de Valencia, 26, pp. 205-214.

BUSTAMANTE-ÁLVAREZ, Macarena; HERAS MORA, Francisco J.; HUGUET ENGUITA; Esperança; IBORRA ERES, M. Pilar; MALIGNAS, Adrien; PRINCIPAL I PONCE, Jordi; RIBERA I LACOMBA, Albert. 2020: "Vía degli Augustali VII 4, 28: las evidencias cerámicas de una fosa singular de mediados del siglo II a.C." En M. OSANNA y L. TONIOLO (cur.): Fecisti Cretaria.
Dal frammento al contesto: studi sul vasellame ceramico del territorio vesuviano. Roma: «l'Erma» di Bretschneider, 2020 (Studi e ricerche del Parco Archeologico di Pompei, 40), pp. 281296.

CAMPS I COLL, Juan; VALLESPIR I BONET, Antonio. 1998: Excavacions a Santa Ponça. Mallorca. El turó de les Abelles, La deixa, 1. Monografies de Patrimoni Històric. Consell de Mallorca. Palma. CERDÁ, Damián. 1980: Excavaciones arqueológicas submarinas en la ensenada de la Colonia de Sant Jordi (Ses Salines-Mallorca). Mapa-catálogo editado con motivo de la Exposición monográfica de los hallazgos efectuados en el yacimiento A. Palma de Mallorca.

DÍAZ GARCÍA, Moisés 2000: "Tipocronologia de los contextos cerámicos tardo-republicanos en Tarraco". Empúries, 52, , pp. 202-260.

ESTARELLAS ORDINAS, M. Magdalena; CARDELL PERELLÓ, Jaume; MERINO SANTISTEBAN, Josep; TORRES ORELL, Francisca. 2020: “Una singular peça ceràmica trobada a Son Espases de Palma (Mallorca)". En X. AQUILUÉ; J. BELTRÁN DE HEREDIA; À. CAIXAL; J. FIERRO y H. KIRCHNER (eds.): Estudis sobre ceràmica i arqueologia de l'arquitectura. Homenatge al Dr. Alberto López Mullor, pp. 75-80.

DUARTE MARTÍNEZ, Francesc-Xavier. 2016: L'avinguda d'Espanya, 3 (Eivissa). Un taller púnic de producció ceràmica. Ceràmiques engalbades púnico-hel-lenístiques d'Eivissa. Sagvntvm. Papeles Del Laboratorio de Arqueología de Valencia, 18. Univesidad d Valencia. Valencia.

FERNÁNDEZ GÓMEZ, Jorge H.; RAMON TORRES, Joan. 1974: "Hallazgo de una necrópolis en Sant Antoni de Portmany". Eivissa, 6, 3를 ep, pp. 30-34.

FERNÁNDEZ GÓMEZ, Jorge H. 1992: Excavaciones en la necrópolis del Puig des Molins (Eivissa). Las campañas de D. Carlos Román Ferrer: 1921-1929. Trabajos del Museo Arqueológico de Ibiza, 28-29.

FERNÁNDEZ GÓMEZ, Jorge H.; COSTA RIBAS, Benjamín. 1998: "La cerámica común púnico-ebusitana: precisiones tipológicas y cronológicas sobre algunas formas cerradas". Misceláneas de arqueología ebusitana, I, TMAEF, 42, pp. 2381.

FERNÁNDEZ GÓMEZ, Jorge H.; GRANADOS, Josep 0. 1980: "Cerámicas de imitación áticas del Museo Arqueológico de Ibiza”. Trabajos del Museo Arqueológico de Ibiza, 2, pp. 24-30. 
GASSNER, Verena; TRAPICHLER, Meri; SAUER, R. 2014. "Pottery production at Velia: Archaeometric Analyses and the Typological Development of Glazed Ware, Coarse Ware and Transport Amphorae." En G. GRECO y L. CICALA (eds.): Archaeometry. Comparing experiences, Quaderni del Centro Studi Magna Grecia, 19, pp. 191-269. Naus. Nápoles.

GÓMEZ BELLARD, Carlos; GURREA BARRICARTE, Rosa. 1985: "Algunas formas de la cerámica de cocina púnico-ebusitana". Archivo español de arqueología, 58, pp. 139-154.

GÓMEZ BELLARD, Carlos. 1995: "Un vertedero púnico rural en Ibiza: S'Olivar d'es Mallorquí". SAGVNTVM. Papeles del Laboratorio de Arqueología de Valencia, 28, pp. 151-165.

GUERRERO AYUSO, Víctor Manuel. 1984: Asentamiento púnico de na Guardis. Excavaciones Arqueológicas en España, 133. Ministerio de Cultura, Dirección General de Bellas Artes y Archivos, Subdirección General de Arqueología y Etnografía. Madrid.

GUERRERO AYUSO, Víctor Manuel. 1995: "La vajilla púnica de usos culinarios". Rivista di Studi Fenici, XXIII-1, pp. 61-99.

GUERRERO AYUSO, Víctor Manuel. 1997: Colonización púnica de Mallorca. La documentación arqueológica y el contexto histórico. Editorial El Tall. Palma.

GUERRERO AYUSO, Víctor Manuel. 1999: La cerámica protohistórica a torno de Mallorca (s. VI-I a.C.). BAR International Series 770.

HOWLAND, Richard Hubbard. 1958: Greek Lamps and their Survivals. The Athenian Agora. Results of Excavations Conducted by The American School of Classical Studies at Athens IV. Princeton.

LANCEL, Serge. 1987: "La céramique punique d'époque hellénistique ". Céramiques hellenistiques et romaines, II, pp. 99-137.

MARÍ, Juan J.; GRAZIANI, Glenda. 2013: “Excavacions arqueològiques a la carretera PM-804". Quaderns d'Arqueologia Ebusitana, 3, pp. 6490

MATAMOROS, Consuelo. 1989: “Las monedas procedentes de una alfarería púnica de Ibiza". $S A$ GVNTVM. Papeles del Laboratorio de Arqueología de Valencia, 22, pp. 267-289.

PÉREZ BALLESTER, José. 2012: “Sobre cerámicas Helenísticas en Iberia / Hispania. Significado y funcionalidad". Archivo Español de Arqueología, 85, pp. 65-78.
PÉREZ BALLESTER, José. 2018: “Cerámicas engobadas púnico-helenísticas de Ibiza y Cerdeña (siglos III-II a.C.). Ordenación funcional". Spal, 27.2, pp. 165-199.

PÉREZ BALLESTER, José; GÓMEZ BELLARD, Carlos. 2009: El depósito rural púnico de can Vicent d'en Jaume (Santa Eulària des Riu, Ibiza). Trabajos del Museo Arqueológico de Ibiza y Formentera, 63. Museo de Arqueología. Ibiza.

PRINCIPAL I PONCE, Jordi; RIBERA I LACOMBA, Albert. 2013: "El material más apreciado por los arqueólogos. La cerámica fina. La cerámica de barniz negro". En A. RIBERA (coord.): $M a-$ nual de cerámica romana: del mundo helenístico al Imperio Romano, pp. 41-146. Comunidad de Madrid, Museo Arqueológico Regional, Colegio de Doctores y Licenciados en Filosofía y Letras y en Ciencias de la Comunidad de Madrid. Madrid.

RAMON TORRES, Joan; ESQUEMBRE BEBIÁ, Marco Aurelio. 2017: "Estructuras urbanas fundacionales de época fenicia en el castillo de Ibiza". En F. PRADOS y F. SALA (eds.): El oriente de occidente. Fenicios y púnicos en el área ibérica, VIII edición del coloquio internacional del CEFYP en Alicante (Alicante - Guardamar, 7-9 nov. 2013), pp. 405-432. Publicacions de la Universitat d'Alacant.

RAMON TORRES, Joan; HERMANNS, Marcus Henrich. 2012: "Aspectos comerciales acerca de dos fragmentos de cerámica ática procedentes del Puerto de Ibiza". Trabajos de Prehistoria, 69, pp. 385-393.

RAMON, Joan; PONS, Octavio. 2017: "Materiales inéditos de los siglos VI-II a.C., procedentes de Ibiza, conservados en el museo de Menorca". Materialidades. Perspectivas en cultura material, 5, pp. 91-120.

RAMON TORRES, Joan; CAU ONTIVEROS, Miguel Ángel. 1997: “Niveles de época vándala de es Castell (Eivissa)". Contextos ceràmics d'època romana tardana $i$ de l'alta edat mitjana (segles IV-X). Taula Rodona (6-8 de novembre de 1996, Badalona). Arqueo Mediterrània 2, Treballs de l'Àrea d'Arqueologia de la Universitat de Barcelona, pp. 269-311.

RAMON TORRES, Joan. 1981a: La producción anfórica púnico-ebusitana. Delegación del Ministerio de Cultura, Ibiza.

RAMON TORRES, Joan. 1981b: "Ibiza y la circulación de ánforas fenicias y púnicas en el Mediterráneo occidental". Trabajos del Museo Ar- 
queológico de Ibiza, 5, Ibiza.

RAMON TORRES, Joan. 1985: "Les amforetes Eb. 77 i algunes formes connexes de la producció cerámica púnico-ebusitana tardana”. Eivissa 3a época, 15-16, pp. 52-58.

RAMON TORRES, Joan. 1990-1991: "Barrio industrial de la ciudad púnica de Ibiza: "El Taller AE-20". Cuadernos de Prehistoria y Arqueología Castellonenses, 15. , pp. 247-285.

RAMON TORRES, Joan. 1991: "Las ánforas púnicas de Ibiza”. Trabajos del Museo Arqueológico de Ibiza, 23. Ibiza.

RAMON TORRES, Joan. 1993: "IM-50. Eivissa". Gala. Revista d'Arqueologia, Antropologia i Patrimoni, 2, pp. 69-88.

RAMON TORRES, Joan. 1994a: "El pozo púnico del 'hort d'en Xim' (Eivissa)". Trabajos del Museo Arqueológico de Ibiza, 32, pp. 1-83.

RAMON TORRES, Joan. 1994b: "El nacimiento de la ciudad fenicia de la bahía de Ibiza". Coloquios de Cartagena I: El Mundo Púnico. Historia, Sociedad y Cultura (Cartagena, nov. 1990), Biblioteca Básica Murciana, Extra 4, pp. 325-368.

RAMON TORRES, Joan. 1995: Las ánforas fenicio-púnicas del Mediterráneo Central y Occidental. Instrumenta 2. Publicaciones de la Universidad de Barcelona. Barcelona.

RAMON TORRES, Joan. 1997: “FE-13. Un taller alfarero de época púnica en ses Figueretes (Eivissa)". Trabajos del Museo Arqueológico de Ibiza y Formentera, 39, pp. 1-193.

RAMON TORRES, Joan. 1998: "La facies cerámica de importación en Eivissa durante el siglo III". En J. RAMON; J. SANMARTÍ; D. ASENSIO y J. PRINCIPAL (eds. cient): Les fàcies ceràmiques d'importació a la costa ibèrica, les Balears i les Pitiüses durant el segle III aC i la primera meitat del segle II aC. Arqueo Mediterrània, Treballs de l'Àrea d'Arqueologia de la Universitat de Barcelona, pp. 157-173. Universidad de Barcelona. Barcelona.

RAMON TORRES, Joan. 2000: Estudi arqueològic $i$ històric del castell d'Eivissa. I. Estructures i elements arquitectònics. Consell Insular d'Eivissa i Formentera. Ibiza.

RAMON TORRES, Joan. 2001: "El asentamiento rural y los enterramientos púnicos de ca n’Eloi (Santa Eulària des Riu, Eivissa". Rivista di Studi Fenici, XXIX-1. Roma, pp. 53-101.

RAMON TORRES, Joan. 2004: "Les àmfores d'importació a l'Eivissa feniciopúnica (s. -VII/-IV)". En J. SANMARTÍ (coord.): La circulació d'àmfo- res al Mediterrani occidental durant la protohistòria (segles VIII-III aC): aspectes quantitatius i anàlisi de continguts, pp. 265-282. Arqueo Mediterrània 8, Treballs de l'Àrea d'Arqueologia. Universitat de Barcelona. Barcelona.

RAMON TORRES, Joan 2011: "El sector alfarero de la ciudad púnica de Ibiza". XXV Jornadas de arqueología fenicio-púnica, TMAEF, 66, pp. 125-182.

RAMON TORRES, Joan. 2012a: "L'évolution urbaine et périurbaine de la ville punique d'Ibiza". En M.C. BELARTE y R. PLANA (eds.): Le paysage périurbain en Méditerranée occidentale pendant la Protohistoire et l'Antiquité. Actes $d u$ Colloque international (6-8 mayo 2009), pp. 245-258. Institut Catalan d'Archéologie Classique. Tarragona.

RAMON TORRES, Joan. 2012b: "La cerámica púnico-ebusitana en época tardía (siglos III-I a.C.)”. En D. BERNAL, y A. RIBERA, Albert (eds.): Cerámicas hispanorromanas II, pp. 627-661. Servicio de Publicaciones de la Universidad de Cádiz. Cádiz.

RAMON TORRES, Joan. 2012c: "RA-91, un pozo púnico del siglo -V en la ribera NW de la bahía de Ibiza". En C. DEL VAIS (cur.): EPI OINOPA PONTON. Studi sul Mediterraneo antico in ricordo di Giovanni Tore, pp. 587-612. Oristano.

RAMON TORRES, Joan. 2014: “Un depósito ritual tardo-púnico de pequeños vasos frente a la playa des Codolar. Ibiza)". SPAL, 23, pp. 137-146.

RAMON TORRES, Joan. 2017: "Pecios y ¿colonias? Materiales púnicos en las Islas Baleares". Menorca entre fenicios y púnicos, publicaciones del CEPOAT 2, 25, pp. 41-84.

RAMON TORRES, Joan. 2020: "Conflit et violence chez les Phéniciens d'Ibiza à l'époque archaïque?". En M. GUIRGUIS; S. MUCUSO y R. PLA (cur.): Cartagine, il Mediterraneo centro-occidentale e la Sardegna. Società, economia e cultura materiale tra Fenici e autoctoni. Studi in onore di Piero Bartoloni I. Le Monografie della SAIC della Società Scientifica "Scuola Archeologica Italiana di Cartagine", pp. 205-236. SAIC editore.

RIBERA I LACOMBA, Albert. 2013: "Los pecios del litoral ibérico y la fundación (138 a.C.) y la destrucción de Valentia (75 a.C.)". En G. OLCESE (ed.): Inmensa Aequora 3. Ricerche archeologiche, archeo-metriche e informatiche per la ricostruzione dell'economia e dei commerci nel bacino occidentale del Mediterraneo (metà IV 
sec. a.C. - I sec. d.C.). Ati del convegno Roma 2426 gennaio 2011, pp. 455-468.

SANMARTÍ GREGO, Enric; PRINCIPAL PONCE, Jordi. 1998: "Cronología y evolución tipológica de la Campaniense A del siglo II a.C.: Las evidencias de los pecios y de algunos yacimientos históricamente fechados". En J. RAMON y E. SANMARTÍ (eds.): Les fàcies ceràmiques d'importació del segle III aC i la primera meitat del segle II aC a la costa central de Catalunya, pp. 193-216. Arqueo Mediterrània, 4, Treballs de l'Àrea d'Arqueologia de la Universitat de Barcelona. Barcelona.

SINTES OLIVES, Elena; RAMON TORRES, Joan. 2019: "Novesdades sobre el factor púnic a Menorca: les excavacions de 2007 a l'església de Santa Eulàlia (Alaior)". BSAL, 75, pp. 15-41. Palma.

VEGAS MINGUELL, Mercedes. 1973: Cerámica común romana del Mediterráneo occidental. Instituto de Arqueología y Prehistoria. Barcelona. VEGAS MINGUELL, Mercedes. 1999: "Phöniko-punische Keramik aus Karthago". En F. RAKOB (ed.): Die deutschen Ausgrabungen in Karthago (Karthago III), pp. 93-219. Mainz a. Rh.

VERDÚ PARRA, Enric. 2015: La necrópolis ibérica de l'Albufereta (Alacant): ritos y usos funerarios en un contexto de interacción cultural. MARQ, Diputación de Alicante.

\section{Apéndice}

\section{EL GRAFITO PÚNICO SOBRE EL JARRO 1212/7}

José A. Zamora, Científico titular CSIC

El grafito sobre el jarro (1212/7) (Figuras 2 y 10), una secuencia de al menos tres signos (el primero incompleto; los anteriores, si los hubo, perdidos) está trazado con firmeza y seguridad, pero sin demasiado esquematismo (su autor no renunció a dar la curvatura debida a alguno de los trazos). No es sin embargo particularmente cursivo en su trazado, aunque presenta claramente un signo de tradición cursiva (el mejor y el único con seguridad completo, el último). El uso epigráfico de este tipo de signos (la escritura neopúnica) remite habitualmente a periodos posteriores a la caída de Cartago, aunque ya en la primera mitad del s. -II tenemos usos ocasionales de esta tipología de signos en inscripciones lapídeas y no resulta pues excesivamente extraña, preexistiendo su uso sobre otros soportes, su aparición en un grafito incluso del s. -III.
Si todos los signos pertenecían a la tradición cursiva, el primero (una decidida línea recta, prolongada bajo la línea de escritura) debería ser casi obligatoriamente una resh; la segunda una nun o, visto que el trazo superior es interrumpido por la rotura, también lamed; la última, el aspa con el ápice en el vértice en alto a la izquierda, debería ser una mem (resultaría más extraño un áleph con tal ápice cambiado]. La lectura sería por tanto [ ... ] rl $/ \mathrm{nm}$.

Aunque pudo siempre tratarse de un término plural, relativo al contenido del contenedor (o a un grupo de emisarios/receptores, como parece ser el caso en el grafito arcaico de la Playa de Camposoto, en el área gaditana) el contenido habitual de estos grafitos, nombres personales, sugeriría la presencia también en el nuevo grafito de un antropónimo, que sin embargo no resulta fácil de reconstruir partiendo de los nombres fenicios atestiguados. Podría intentar leerse el primer signo como parte de una gimel incompleta, de trazo izquierdo corto y astil recto (como aparecen en algunos epígrafes tardíos) para leer [ $\mathrm{m}] \mathrm{gnm}$; pero la total ausencia de la característica curva del asta de la gimel (curva que otros trazos del grafito sí presentan) plantearía dudas. Pudo siempre tratarse de un antropónimo no atestiguado (de hecho, no son extraños los de formante final -m).

Otra posibilidad interpretativa muy probable en un grafito sobre contenedor cerámico sería la presencia de un topónimo. En este caso, además de hipotetizar nombres de lugar aún no atestiguados, podría proponerse (siempre de forma especulativa, dada la condición incompleta del grafito) alguno ya conocido: 'yrnm (el nombre fenicio de la isla de Pantelería). El topónimo encajaría perfectamente entre las reconstrucciones posibles del grafito (habría que integrar ['y] rnm), pudiendo indicar el origen o, más bien, el destino del contenedor y de su contenido (dado su segura factura en Ibiza). Su amortización también en Ibiza (que sugiere una circulación local) aunque no imposibilita la hipótesis, la dificulta, recordándonos de nuevo la prudencia necesaria en este tipo de reconstrucciones e interpretaciones. 